\title{
An integrative approach to assess environmental and economic sustainability in multi-tier supply chains
}

\author{
Multi-tier supply chain sustainability is paramount to achieve corporate \\ sustainability, due to the significant impacts from organisations beyond the focal \\ firm boundaries and its direct suppliers. However, including environmental \\ considerations within the dominant profit-centric logic of supply chain related \\ decisions is prone to generate sustainability tensions.
}

This work aims to support organisations address tensions between sustainability dimensions by adopting an integrative approach for sustainable supply chain management performance assessment thanks to an innovative eco-intensity based performance assessment method, which achieves a balanced consideration of environmental and economic performance in a weak sustainability perspective. The method, using primary data sourced from actual practice and featuring an indirect multi-tier approach with decentralised responsibilities across organisations, is applied to a case study of a machinery supply chain.

The proposed integrative approach can support addressing sustainability tensions in the area of sustainable supply chain management, facilitate sustainable supplier evaluation and identify supply chain hotspots for operational improvement.

Keywords: sustainability performance assessment; multi-tier supply chain; ecointensity; integrative approach; tensions; 


\section{Introduction}

Organisations are facing mounting pressure from multiple stakeholders to consider sustainability concerns within their operations, due to the substantial impact industrial activities have on both the environment and the society (Bask et al. 2013; Frota Neto et al. 2008; Björklund, Martinsen, and Abrahamsson 2012; Montoya-Torres, GutierrezFranco, and Blanco 2015). This pressure initially targeted single organisations, however it later expanded to include the wider supply chain, as it was recognised that the majority of the environmental impacts in a typical supply chain arises beyond the boundaries of the focal firm (Beavis 2015; Veleva et al. 2003). While sustainability challenges have become a supply chain-wide issue (Varsei et al. 2014; Sigala 2008; Marshall et al. 2014), focal companies are still largely considered liable for the unsustainable behaviours of the supply chain by stakeholders (Gimenez and Tachizawa 2012; Hartmann and Moeller 2014; Savino, Manzini, and Mazza 2015). Focal companies typically have a prominent and powerful position within the supply chain, since they hold the contacts with the final customers or are responsible for designing the final product offered to the market (Seuring and Müller 2008). Moreover, they make sourcing decisions and manage relationships to supply chain actors, whom they are often able to influence (Brennan and Tennant 2018).

However, focal companies still encounter difficulties to monitor the sustainability performance of their supply chains due to limited visibility and traceability of lower-tier suppliers (Acquaye et al. 2014; Michelsen and Fet 2010; Egilmez et al. 2014). The efforts of focal companies are further hampered by the increasing length and complexity of contemporary global supply chains (Mena, Humphries, and Choi 2013), calling for effective methods to holistically evaluate the wider supply chain performance (Fabbe-Costes, Roussat, and Colin 2011). 
Nevertheless, existing supply chain sustainability performance assessment methods available in the literature have largely limited the assessment scope to focal companies, first tier suppliers and first tier customers only, potentially underestimating the impact of the entire supply chain (Ahi and Searcy 2015; Tuni, Rentizelas, and Duffy 2018). On the other hand, methods aiming to extend the performance assessment to lower-tier upstream suppliers either do not consider the multiple-organisations nature of the majority of the supply chains, assuming the existence of a central administration of the supply chain, or adopt environmental values based on database sources, thus not capturing at an adequate level of granularity the potentially different environmental performance of similarly structured supply chains (Tuni and Rentizelas 2018).

This work thus first introduces an empirical application of a multi-tier supply chain sustainability performance assessment method adopting primary data sourced from actual practice. The application scope includes environmental and economic aspects. The method extends the assessment to include lower-tier suppliers, while still respecting the multiple-organisation nature and non-collaborative characteristics of the majority of real life supply chains. This is performed thanks to a decentralised indirect approach, establishing contact with lower-tier suppliers through $1^{\text {st }}$ tier suppliers, and materialised through a recursive mechanism to pass sustainability information from one tier to the next, which does not require the full visibility of the extended supply chain by any member of the supply chain. The assessment is carried out through a set of ecointensity indicators that relate the environmental performance of the supply chain to its economic output. The adoption of eco-intensity to assess the sustainability performance of the supply chain is embedded in the concept of weak sustainability, which implies a perfect substitutability between the manufactured capital and the natural capital (Ness et al. 2007; Ukidwe and Bakshi 2005). As such, eco-intensity features an integrative 
approach to address tensions between sustainability dimensions, thus moving beyond the dominant instrumental approach to implement strategy in the existing sustainable supply chain management literature (Van der Byl and Slawinski 2015).

By adopting an integrative approach to assess the sustainability performance of multi-tier supply chains, this work thus aims to support organisations addressing tensions between sustainability dimensions by achieving a balanced integration of the environmental and economic dimensions of sustainability. This is demonstrated through a case study application in the machinery industry. Thereby, the work directly contributes to tackle the "lack of empirical studies examining how firms effectively integrate the dimensions of sustainability without focusing on win-wins, trade-offs, and more generally, profits” (Van der Byl and Slawinski 2015).

The remaining part of the paper is organised as follows. 'Background and Literature Review' provides details about multi-tier sustainable supply chain management (SSCM), eco-efficiency and eco-intensity based models in SSCM as well as on tensions arising in SSCM. 'Materials and methods' introduces the case study and briefly overviews the method adopted to assess the sustainability performance of the supply chain. The outputs of the application of the method are displayed in the 'Results' section. Finally, implications for practitioners and theory along with the limitations of the research are illustrated in the 'Discussion' section, before the final remarks in the 'Conclusion' section.

\section{Background and Literature Review}

This work is interdisciplinary in nature, lying at the intersection of SSCM and performance assessment fields, focusing specifically on multi-tier SSCM. The method applied is interpreted through the lens of tensions in corporate sustainability via a case study application, focusing on the strategy implementation aspect within the supply 
chain. Accordingly, background information is provided for three key areas: multi-tier SSCM, performance assessment in SSCM with a focus on eco-efficiency and ecointensity models, and tensions in SSCM.

\section{Multi-tier SSCM}

Organisations are required to understand not only their first-tier suppliers environmental performance but also to capture the environmental profiles of the lower-tier suppliers in order to avoid underestimating the actual environmental impact of the supply chain (Genovese et al. 2013; Miemczyk, Johnsen, and Macquet 2012). This is particularly critical in the contemporary competitive environment, characterised by long and complex supply chains due to increasing outsourcing and offshoring practices (Mena, Humphries, and Choi 2013; Dey and Cheffi 2013). A number of large multinational groups, including Nike, Unilever and Nestlé, were confronted with social and environmental scandals caused by unsustainable behaviours of their lower-tier suppliers leading to corporate reputation damage and economic losses (Miemczyk, Johnsen, and Macquet 2012; Vachon and Mao 2008; Jabbour, de Sousa Jabbour, and Sarkis 2018).

Focal companies may embrace a number of approaches to deal with lower-tier suppliers. In their work focused on a three-tiers supply chain, Mena, Humphries, and Choi (2013) identified open, transitional and closed triads as the options faced by focal firms to interact with each supplier's supplier, depending on the existence and nature of the contact between focal company and $2^{\text {nd }}$ tier suppliers. A similar framework is proposed by Tachizawa and Wong (2014), who focused specifically on multi-tier sustainable supply chains and extend their focus to any lower-tier supplier beyond triadic supply chains. Focal companies can select from four potential approaches to deal with lower-tier suppliers regarding sustainability, as illustrated in Figure 1: 'Don't bother', 'Working with third party', 'Direct' and 'Indirect'. These approaches are 
typically implemented separately, although hybrid approaches have emerged recently as a combination of 'Direct' and 'Indirect' approach (Dou, Zhu, and Sarkis 2017) or as in the cascaded approach proposed by Sauer and Seuring (2018), which prescribes two focal companies managing separately the upstream and downstream supply chain according to one of the approaches illustrated in Figure 1. While the 'Don't bother' approach entails either focal companies having no information about the sustainability of lower-tier suppliers or a substantial inability to influence them, the 'Direct' approach implies a stringent control of focal companies over lower-tier suppliers (Meinlschmidt, Schleper, and Foerstl 2018; Tachizawa and Wong 2014). The 'Direct' approach can be holistic, thus being applied to all lower-tier suppliers, or be selectively applied to specific products or geographical region (Meinlschmidt, Schleper, and Foerstl 2018). Finally, two intermediate options are faced by focal firms that can reach indirectly the lower-tier suppliers either through third parties, such as non-governmental organisations, industry associations or governmental bodies, or through their $1^{\text {st }}$ tier suppliers. The 'Third party' approach, also referred as alliance-based indirect approach, rely on external entities to elaborate sustainability standards and monitor lower-tier suppliers (Meinlschmidt, Schleper, and Foerstl 2018; Tachizawa and Wong 2014). The 'Indirect' approach instead implies that the focal company establishes a contact with sub-suppliers through a tier-1 supplier (Tachizawa and Wong 2014), coherently with the dynamic of typical supply chains that are made up by interconnected autonomous entities (Mena, Humphries, and Choi 2013). The approach can be applied consistently through all $1^{\text {st }}$ tier suppliers, thus being a compliance-based indirect approach, or to a sub-set of $1^{\text {st }}$ tier suppliers, which is referred as multiplier-based indirect approach (Meinlschmidt, Schleper, and Foerstl 2018). This logic can be replicated in the upstream supply chain until the n-th tier supplier is reached (Tachizawa and Wong 2014). 


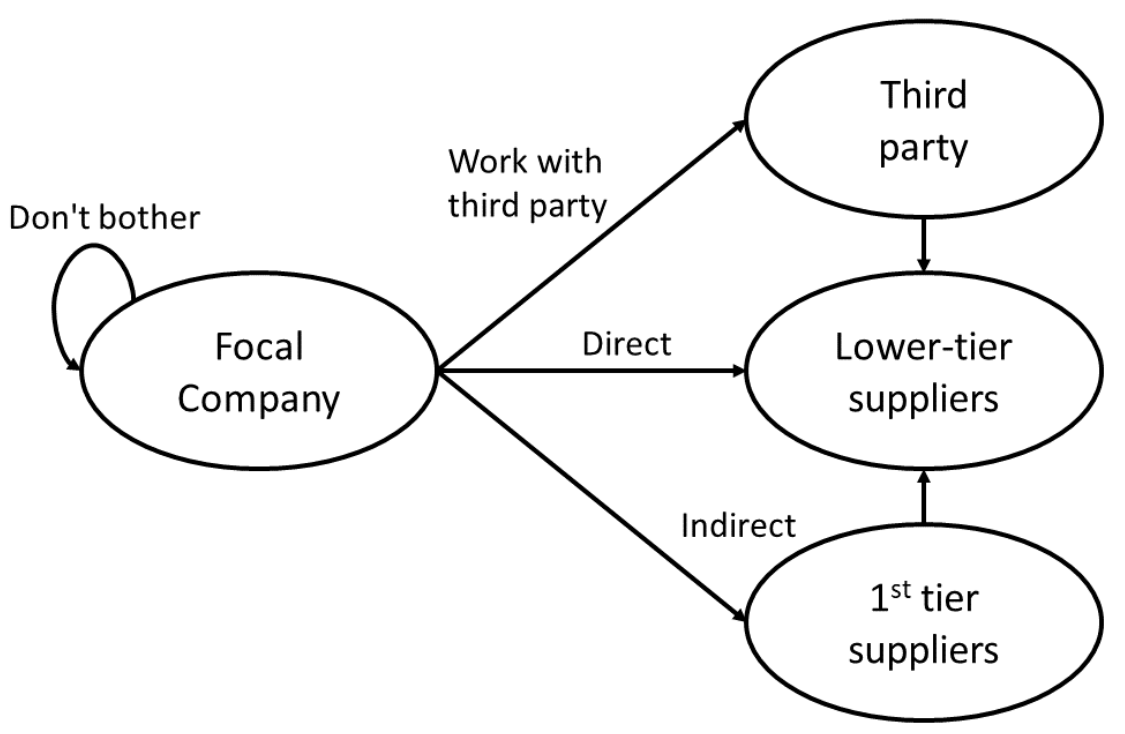

Figure 1. Multi-tier SSCM approaches (adapted from Tachizawa and Wong, 2014)

Wilhelm et al. (2016) built up on the 'Indirect' approach highlighting the challenges associated with other approaches due to the limited control and power of focal companies on lower-tier suppliers and calling for an active role of $1^{\text {st }}$ tier suppliers in disseminating sustainability requirements of focal companies further upstream in the supply chain. The limited applicability of the 'Direct' approach is also reinforced by recent surveys highlighting that companies are less knowledgeable about their upstream supply chain with the majority of supply chain executives admitting that the visibility of their supply chain is limited to $1^{\text {st }}$ tier suppliers (Egilmez et al. 2014; O’Rourke 2014; Acquaye et al. 2014). In light of the above, this work adopts an 'Indirect' multi-tier supply chain approach to reach lower-tier suppliers.

\section{Performance assessment in multi-tier SSCM}

The involvement of multiple organisations in the assessment of the sustainability performance of the supply chain leads to a number of challenges, such as lack of trust, cultural differences, conflicting objectives and inclination towards local optimisation 
rather than systemic approaches (Hervani, Helms, and Sarkis 2005; Taticchi, Tonelli, and Pasqualino 2013; Hassini, Surti, and Searcy 2012). On top of the challenges associated with the relationships among different organisations building the supply chain, there is also a lack of consensus on the metrics to be adopted to assess the sustainability performance due to a low degree of standardisation of indicators (Ahi and Searcy 2015; Tuni, Rentizelas, and Duffy 2018). Quantitative metrics dominate the spectrum of environmental sustainability assessment of supply chains, as they are considered more objective, however both absolute and relative indicators are found in the literature (Ahi and Searcy 2015; Mintcheva 2005; Tsoulfas and Pappis 2008).

Absolute indicators are able to capture the overall environmental performance of the system under analysis, but are prone to fluctuations due to changes in the produced outputs and are not suitable for benchmarking of different systems (Michelsen, Fet, and Dahlsrud 2006; Wiedmann, Lenzen, and Barrett 2009). On the other hand, relative indicators harmonise the environmental impact through reference values such as units produced, weight of products, volume of products or monetary value of products, overcoming such limitations (Mintcheva 2005; Koh et al. 2012). Differently from other reference values, the inclusion of the monetary value of products is applicable with the same logic to any type of product independently of its physical features.

The relationship between the environmental and economic dimensions of sustainability can be expressed as eco-efficiency, which is the ratio of the economic value created and the sum of environmental impacts caused by an economic activity, or as eco-intensity, which is the reverse ratio and is expressed as the environmental impact divided by the economic benefit generated by an activity (WBCSD 2000; Huppes and Ishikawa 2005; Schmidt and Schwegler 2008). Both eco-efficiency and eco-intensity allow integrating in a unique indicator the environmental dimension and the economic 
dimension of sustainability, thus adopting an integrative approach between the dimensions of sustainability.

A number of models using either eco-efficiency or eco-intensity were developed in the SSCM literature, however only few of them adopted a multi-tier perspective going beyond the $1^{\text {st }}$ tier suppliers and direct customers of the focal company, as evidenced in Table 1. Among the works taking a multi-tier perspective, some works, like Michelsen, Fet, and Dahlsrud (2006) and Michelsen and Fet (2010), rely on generic data to model the supply chain sustainability performance but do not consider the actual behaviour of the supply chain, ultimately adopting a focal firm-centric stance. Hence, they are classified as 'Don't bother' in Table 1. A direct approach was instead taken by Quariguasi Frota Neto et al. (2009), who developed a model to calculate ecoefficiency of a reverse chain in the electrical and electronics industry. Empirical data were adopted, but limited to specific production processes within the supply chain. Even the few authors who have developed an indirect multi-tier supply chain approach either did not present applications with empirical data, like Schmidt and Schwegler (2008), or adopted them only for a portion of the supply chain, as in Joa et al. (2014). In contrast to the above, this work uses empirical values also for lower-tier suppliers to assess the eco-intensity of the supply chain.

Table 1. Summary of eco-efficiency and eco-intensity models in SSCM

\begin{tabular}{ccccc}
\hline Source & Indicators & $\begin{array}{c}\text { Supply } \\
\text { chain } \\
\text { extent }\end{array}$ & $\begin{array}{c}\text { Multi-tier } \\
\text { approach }\end{array}$ & Data \\
\hline $\begin{array}{c}\text { (Charmondusit, } \\
\text { Phatarachaisakul, and } \\
\text { Prasertpong 2014) } \\
\left(\begin{array}{c}\text { Colicchia et al. } \\
\text { 2015) }\end{array}\right.\end{array}$ & Eco-efficiency & Dyad & $/$ & Empirical data \\
& Eco-efficiency & Dyad & $/$ & Empirical data
\end{tabular}




\begin{tabular}{|c|c|c|c|c|}
\hline (Joa et al. 2014) & Eco-intensity & Multi-tier & Indirect & $\begin{array}{l}\text { Empirical and } \\
\text { generic data }\end{array}$ \\
\hline $\begin{array}{l}\text { Mahdiloo, Saen, and } \\
\text { Lee 2015) }\end{array}$ & Eco-efficiency & Dyad & l & Empirical data \\
\hline $\begin{array}{l}\text { Michelsen, Fet, and } \\
\text { Dahlsrud 2006) }\end{array}$ & Eco-efficiency & Multi-tier & $\begin{array}{l}\text { Don't } \\
\text { bother }\end{array}$ & $\begin{array}{l}\text { Generic data } \\
\text { (LCA based) }\end{array}$ \\
\hline $\begin{array}{l}\text { (Michelsen and Fet } \\
\text { 2010) }\end{array}$ & Eco-efficiency & Multi-tier & $\begin{array}{l}\text { Don't } \\
\text { bother }\end{array}$ & $\begin{array}{l}\text { Generic data } \\
\text { (LCA based) }\end{array}$ \\
\hline $\begin{array}{l}\text { (Quariguasi Frota } \\
\text { Neto et al. 2009) }\end{array}$ & Eco-efficiency & Multi-tier & Direct & $\begin{array}{l}\text { Empirical and } \\
\text { generic data }\end{array}$ \\
\hline $\begin{array}{c}\text { (Schmidt and } \\
\text { Schwegler 2008) }\end{array}$ & Eco-intensity & Multi-tier & Indirect & No data \\
\hline (Tseng et al. 2013) & Eco-efficiency & Dyad & I & $\begin{array}{c}\text { Based on } \\
\text { experts' opinion }\end{array}$ \\
\hline $\begin{array}{c}\text { (Wu and Barnes } \\
\text { 2016) }\end{array}$ & Eco-efficiency & Triad & l & No data \\
\hline This work & Eco-intensity & Multi-tier & Indirect & Empirical data \\
\hline
\end{tabular}

\section{Tensions in SSCM}

Corporate sustainability tensions can surface when at least two dimensions of triplebottom-line sustainability are conflicting (Daddi et al. 2019). There are four approaches identified to manage tensions arising between the dimensions of sustainability: win-win, trade-off, integrative and paradox (Van der Byl and Slawinski 2015; Brix-Asala et al. 2018).

Win-win and trade-off approaches are classified as instrumental approaches as they primarily focus on the economic dimension in order to maximise profits (Van der Byl and Slawinski 2015). Win-win approach aims to align the environmental and/or social goals to the economic ones avoiding tensions, while trade-off approach accepts the 
impossibility to achieve simultaneously goals in different dimensions of sustainability thus requiring a choice between conflicting goals and dimensions (Van der Byl and Slawinski 2015; Brix-Asala et al. 2018). In this case, the priority is typically given to the economic dimension in order to meet expectations from shareholders and tensions are eliminated by the choice between dimensions of sustainability (Van der Byl and Slawinski 2015).

On the other hand, the integrative approach aims to move beyond instrumental approaches by bringing together the dimensions of sustainability "without favoring any one element" and balancing divergent sustainability objectives (Van der Byl and Slawinski 2015; Hahn et al. 2015). According to the integrative approach, tensions are thus embraced rather than being dismissed and organisations should have different sustainability objectives, even if those are contradictory (Hahn et al. 2015). By integrating in a single indicator the economic and environmental dimensions of sustainability, the eco-intensity concept naturally adopts an integrative approach to the sustainability tensions, as equal importance is given to both dimensions of sustainability. Finally, the paradox approach further expands the integrative approach "acknowledging the coexistence of contradictory elements or tensions" and focusing on understanding their nature and how actors deal with them over time (Van der Byl and Slawinski 2015; BrixAsala et al. 2018).

Tensions in the specific area of sustainable supply chain management have been considered detrimental to the execution of an effective sustainable strategy (Van der Byl and Slawinski 2015). However within SSCM, the integrative and paradox approaches to deal with triple-bottom-line tensions have been largely overlooked in favour of the instrumental approach (Van der Byl and Slawinski 2015). Moreover, studies moving beyond the instrumental approach remained largely conceptual in nature so far, without 
an adequate consideration of how firms can empirically integrate the dimensions of sustainability without having a profit-centric view (Van der Byl and Slawinski 2015). This work thus bridges this gap and provides new insights on the issue of addressing tensions between sustainability dimensions within a multi-tier supply chain context. This is demonstrated by applying an eco-intensity based integrative performance assessment method featuring an indirect multi-tier supply chain approach to an operating supply chain through a case study in the machinery industry.

\section{Materials and methods}

Single case study research is adopted in this work to empirically investigate a contemporary phenomenon within its real-life context (Krikke 2011; Yin 2003), that is in this case the sustainability performance of an operating multi-tier supply chain over a timespan of a year. As the phenomenon of interest is contemporary and is not affected by behavioural events or variables, case study is considered an appropriate research method to investigate the phenomenon (Yin 2003).

Case studies are functional to explore and showcase the applicability of models in specific and real situations (Yin 2003; Genovese et al. 2013). In this work, the case study thus serves the purpose of validating the method in an operating context with primary data and evaluating its applicability. From a practical viewpoint, the case study is helpful in enhancing the understanding of the usefulness of the results obtained in terms of performance improvement for both the focal company and other supply chain tiers, being based on a real context. Finally, the case study is also demonstrating how the proposed integrative approach can contribute to manage tensions between sustainability dimensions in a multi-tier supply chain context, through theoretical reflection on the implementation process and on the results. 


\section{Case study selection}

A holistic single case study was selected on the basis of representativeness (Yin 2003), as the supply chain under analysis is representative of contemporary manufacturing supply chains. Representative features of the supply chain include being spread across several countries as well as a complex structure due to the presence of outsourcing activities. Moreover, the case study was deemed of interest from an environmental perspective, because of the presence of several industrial activities typically associated with high levels of pollution, such as forging, casting and steelmaking (Van Caneghem et al. 2010).

\section{Case study overview}

The investigated case study is an international supply chain operating in the 'Machinery' industry, according to the Global Industry Classification Standard (MSCI 2015), and the final product delivered to the customer is an engine. The supply chain operates in a B2B environment, delivering the product to several customers worldwide.

The three-tiers supply chain is depicted in Figure 2 and in Figure 3. The figures provide different types of information: Figure 2 captures the material flow along the supply chain, providing information about the intermediate products moved between the supply chain members as well as on the selected means of transport, which is truck for every supply chain link. On the other hand, Figure 3Figure 2 illustrates the supply chain links based on monetary flow and indicates the yearly quantities produced and the unitary prices of the intermediate products and the final product. Figure 3 also provides the basis for the implementation of the recursive mechanism moving downstream along the chain as well as for the identification of the environmental hotspots moving upstream along the chain, which are both based on the monetary flow between 
organisations, as detailed in Tuni and Rentizelas (2018). Finally, the boxes representing the organisations in both figures detail which is the core activity of each organisation within the supply chain. Due to the request of the focal company for the supply chain members to remain anonymous for commercial confidentiality purposes, organisations are anonymised through a coding system.

The visual comparison of Figure 2 and Figure 3 highlights a different positioning in the case of companies 2.1 and 2.2. While from the material flow point of view they account as $2^{\text {nd }}$ tier suppliers, they are considered $1^{\text {st }}$ tier suppliers from a monetary flow point of view. The reason for this misalignment lies in the fact that company 2 is actually an outsourcer for the focal company $(F C)$. Therefore, $F C$ has direct business relations with 2, 2.1 and 2.2 and the payments take place directly from $F C$ to each of these organisations. However, the material is shipped from suppliers 2.1 and 2.2 directly to 2 in order to optimise the logistics and minimise the distance travelled by intermediate products. Regardless of this misalignment, the presence of supplier 3.1 defines the multi-tier structure of the supply chain even from the monetary flow perspective.

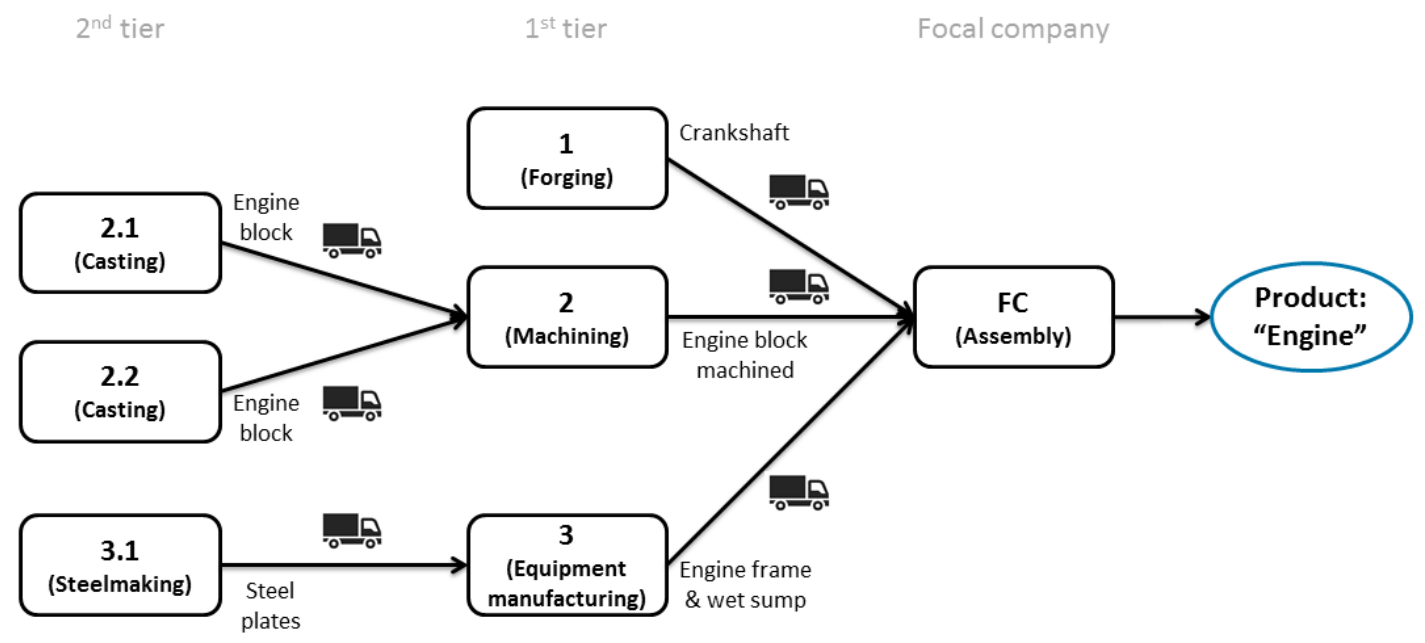

Figure 2. Supply chain material flow 
Overall, seven organisations across three tiers built up the supply chain in its final format under analysis, while an eighth organisation pulled out from the study due to unwillingness of the company to share environmental data of its lower-tier suppliers:

- Focal company $(F C)$ : The core business of the organisation is the production of engines and post-sale servicing of engines, which are used both for fixed and mobile applications. The company assembles the components obtained from its suppliers and produces the final product, which is the engine.

- $1^{\text {st }}$ tier suppliers:

- 1 : the core business of the organisation is the manufacturing of forged steel products. The company produces the crankshaft for the engine.

- 2: the organisation is specialised in subcontracting machining services, with a special focus on heavy-duty precision machining; the company acts as an outsourcer in the supply chain, receiving the engine block from suppliers 2.1 and 2.2 and machining the engine block. The machined engine block is then transported to $F C$.

○ 3: the company is specialised in heavy equipment and steel fabrications; it produces the engine frame and the wet sump for the engine that are then shipped to $F C$.

- 2.1 and 2.2: the core business of both organisations is casting; they both produce the engine block for the final product. The engine block does not reach directly $F C$ but is moved first to supplier 2 for machining.

- $2^{\text {nd }}$ tier supplier: 3.1 is a steel company that is specialised in processing raw materials to steel. The steel plate engine frame and the steel plate oil sump are produced by 3.1 and then sold to organisation 3 . 


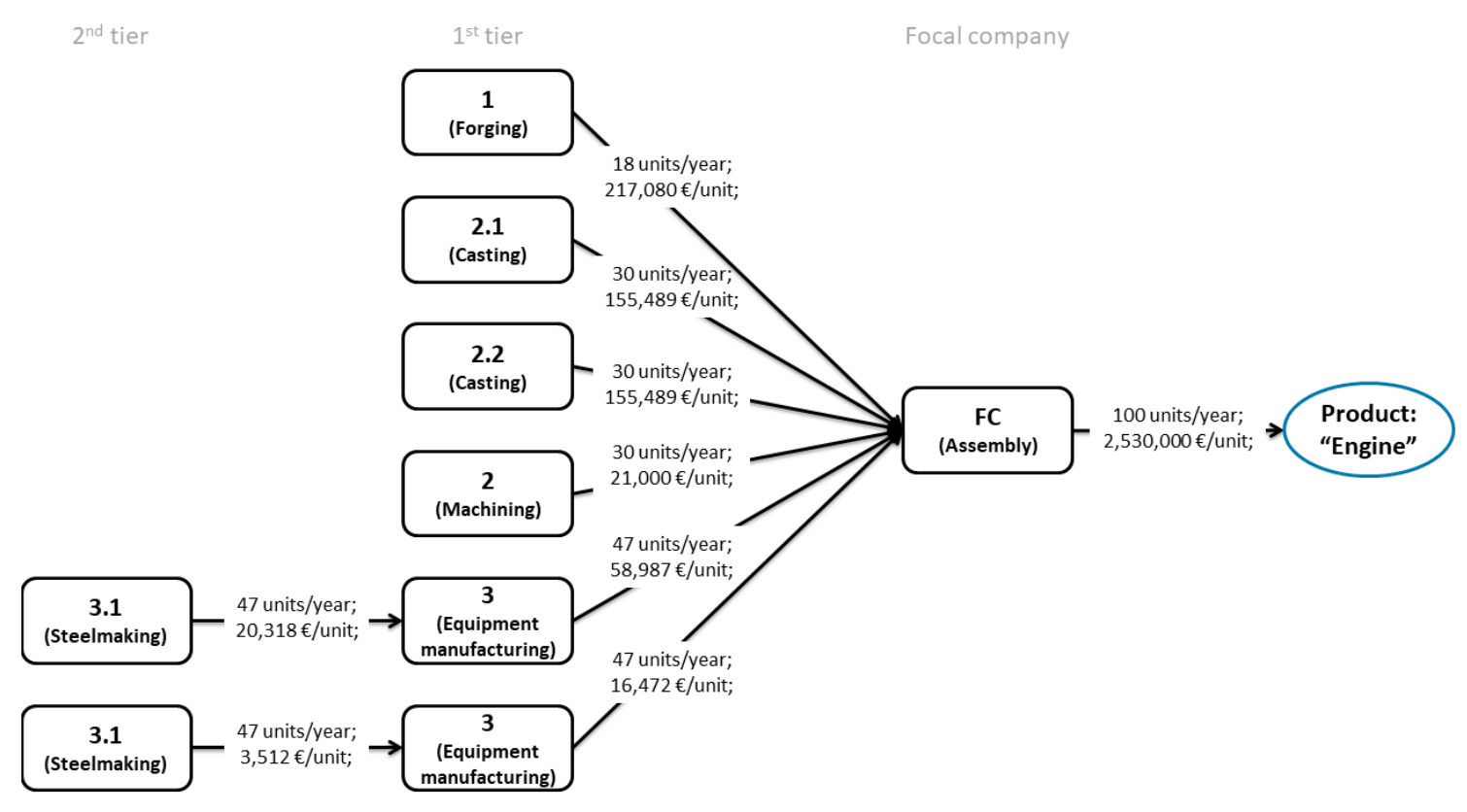

Figure 3. Supply chain monetary flow

According to the European Union enterprises classification, the focal company and the majority of organisations part of the supply chain could be defined as a large enterprises, as they employ more than 250 people and their annual turnover exceeds EUR 50 million (European Union 2003). The only exceptions are suppliers 3 and 2, which can be defined as a medium enterprise and a small enterprise respectively according to the same classification scheme.

Given the complexity of the final product, which includes around 1,000 components sourced from 350 core $1^{\text {st }}$ tier suppliers, this work focused on a critical subsystem of the engine to explore the applicability of the method. The investigated subsystem accounts for one third of the final value of the engine. While this does not allow generalisation about the overall supply chain sustainability performance of the full product, it provides an adequate coverage of a significant share of the final product and some of its most critical component supply chain, including some critical manufacturing 
processes from an environmental perspective. Moreover, the considered sub-system accounts also for one third of the final product weight, which gives significant information in terms of the environmental impact of transport, which is assumed in this work to be proportional with the weight and the distance travelled, in line with Brandenburg (2015).

\section{Data collection}

Data was collected between January 2018 and September 2018. Both environmental and economic data refer to year 2017 . The supply chain manager of $F C$ was the only point of contact for the researchers. A standardised spreadsheet for data collection, available in Appendix 3, was sent to $F C$. The focal company then circulated the spreadsheet to $1^{\text {st }}$ tier suppliers that subsequently reached out the $2^{\text {nd }}$ tier suppliers, passing the environmental pressure information upstream along the chain, coherently with the indirect multi-tier supply chain management approach adopted.

The key environmental information on the organisations part of the supply chain are presented in Table 2. These are represented by six environmental indicators based on Tuni and Rentizelas (2018), which were finalised with the supply chain manager of $F C$ and deemed adequate to represent the performance against the key environmental impact areas of the supply chain. The indicators cover both environmental inputs withdrawn from natural capital as well as environmental outputs released to the environment. The indicators are material consumption, land occupation, water consumption, energy consumption, emissions to air and solid waste. Energy consumption includes both electricity consumption and primary energy consumption due to fuel consumption, while emissions to air captures scope 1 and scope 2 greenhouse gas (GHG) emissions, which are converted to the common unit of 
measurement of $\mathrm{kg} \mathrm{CO}_{2} \mathrm{e}$. The key economic indicators are presented in Table 3. All figures are on a yearly basis and refer to year 2017 .

Table 2. Environmental profile of the organisations

\begin{tabular}{|c|c|c|c|c|c|c|}
\hline 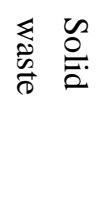 & 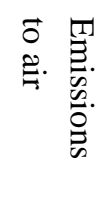 & 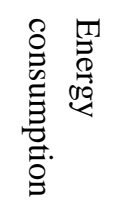 & 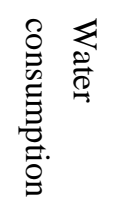 & 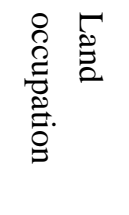 & 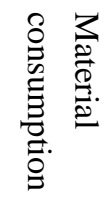 & 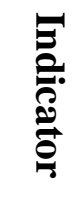 \\
\hline 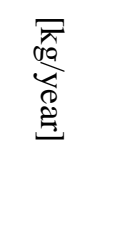 & 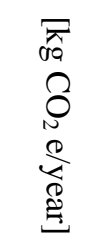 & 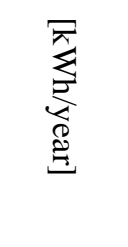 & 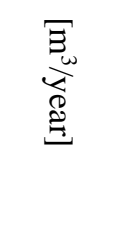 & 昰 & 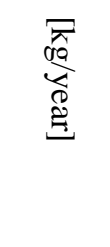 & \\
\hline $\begin{array}{l}\overrightarrow{0} \\
0 \\
0 \\
0 \\
8\end{array}$ & 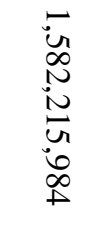 & $\begin{array}{l}\cdot \\
+ \\
0 \\
0 \\
0 \\
N \\
\stackrel{0}{0} \\
\infty\end{array}$ & $\begin{array}{l}\overrightarrow{\tilde{N}} \\
\stackrel{8}{8} \\
\stackrel{8}{8}\end{array}$ & $\begin{array}{l}\tilde{N} \\
\text { ठे } \\
\stackrel{8}{8}\end{array}$ & 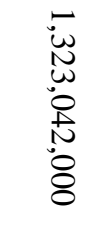 & - \\
\hline $\begin{array}{l}\mathbf{N} \\
\infty \\
\stackrel{N}{N}\end{array}$ & 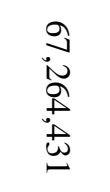 & 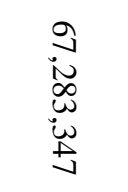 & $\begin{array}{l}\text { ŭ } \\
\ddot{8}\end{array}$ & $\begin{array}{l}\overrightarrow{0} \\
\dot{8}\end{array}$ & 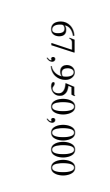 & $\stackrel{N}{N}$ \\
\hline $\begin{array}{l}\overrightarrow{0} \\
\dot{\infty} \\
8 \\
\dot{8} \\
8\end{array}$ & 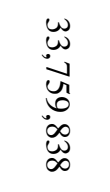 & $\begin{array}{l}W \\
N \\
\stackrel{N}{N} \\
N \\
\pm \\
\pm\end{array}$ & $\begin{array}{l}\overline{\breve{a}} \\
\ddot{\ddot{g}}\end{array}$ & $\begin{array}{l}\text {. } \\
\text { \&े }\end{array}$ & $\begin{array}{l}0 \\
0 \\
8 \\
8\end{array}$ & $\stackrel{N}{N}$ \\
\hline 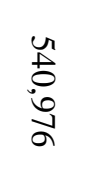 & $\begin{array}{l}\vec{w} \\
\stackrel{ \pm}{ \pm} \\
\stackrel{\infty}{\infty}\end{array}$ & 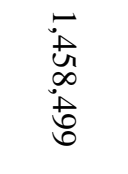 & $\overrightarrow{\stackrel{\circ}{\circ}}$ & $\begin{array}{l}\circ \\
\ddot{\sigma}\end{array}$ & 0 & $N$ \\
\hline $\begin{array}{l}\vec{D} \\
\infty \\
\stackrel{N}{ } \\
\infty \\
\dot{8} \\
8\end{array}$ & $\begin{array}{l}\tilde{N} \\
\stackrel{t}{ \pm} \\
\dot{0} \\
\infty \\
\stackrel{+}{ \pm} \\
\pm \\
\pm\end{array}$ & 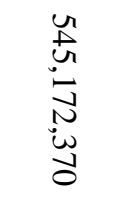 & $\begin{array}{l}\overrightarrow{0} \\
\infty \\
0 \\
0 \\
\stackrel{8}{8}\end{array}$ & $\begin{array}{l}\ddot{u} \\
\ddot{\tilde{o}} \\
\dot{8}\end{array}$ & $\begin{array}{l}0 \\
0 \\
0 \\
0 \\
0 \\
0 \\
8 \\
\alpha\end{array}$ & سِ \\
\hline
\end{tabular}




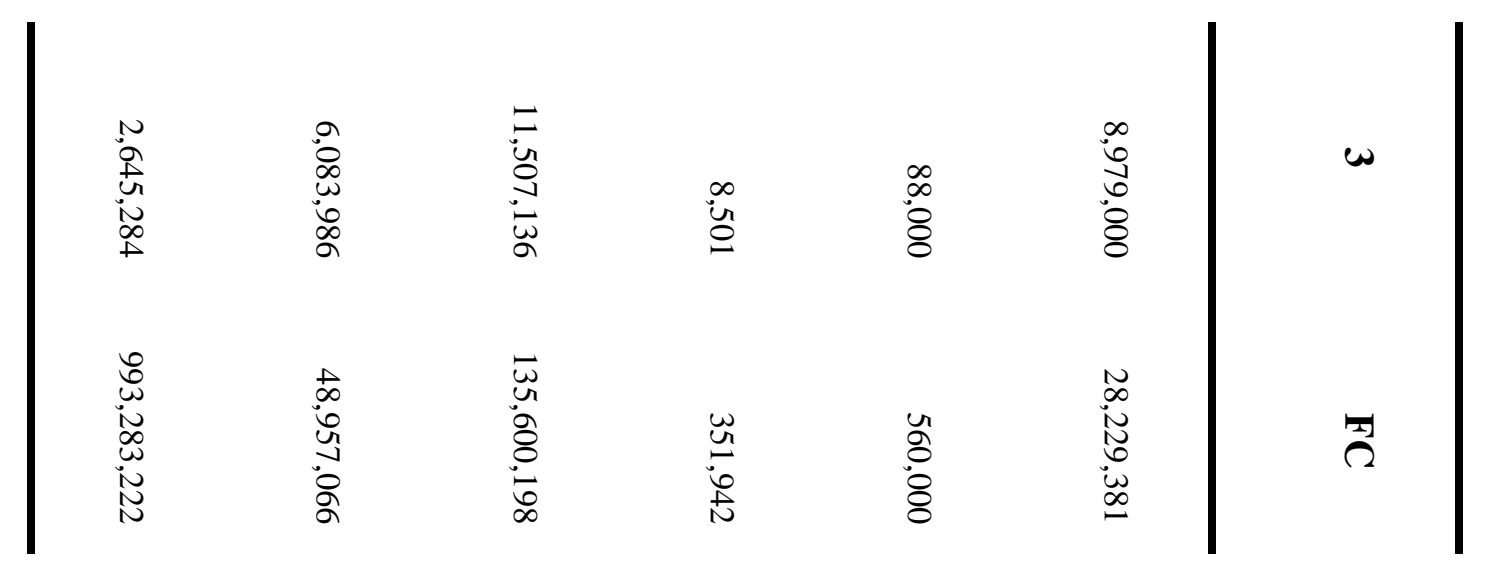

The turnover generated by the investigated supply chain for $F C$ refers to the entire product 'Engine', while only a sub-system of the product is analysed in the case study. This value thus required further adjustment to take this aspect into consideration, as next section details. Other values in the same row do not require any further adjustment as the turnover generated by intermediate products fully contribute to the supply chain of the sub-system of the product under analysis.

Table 3. Economic profile of the organisations

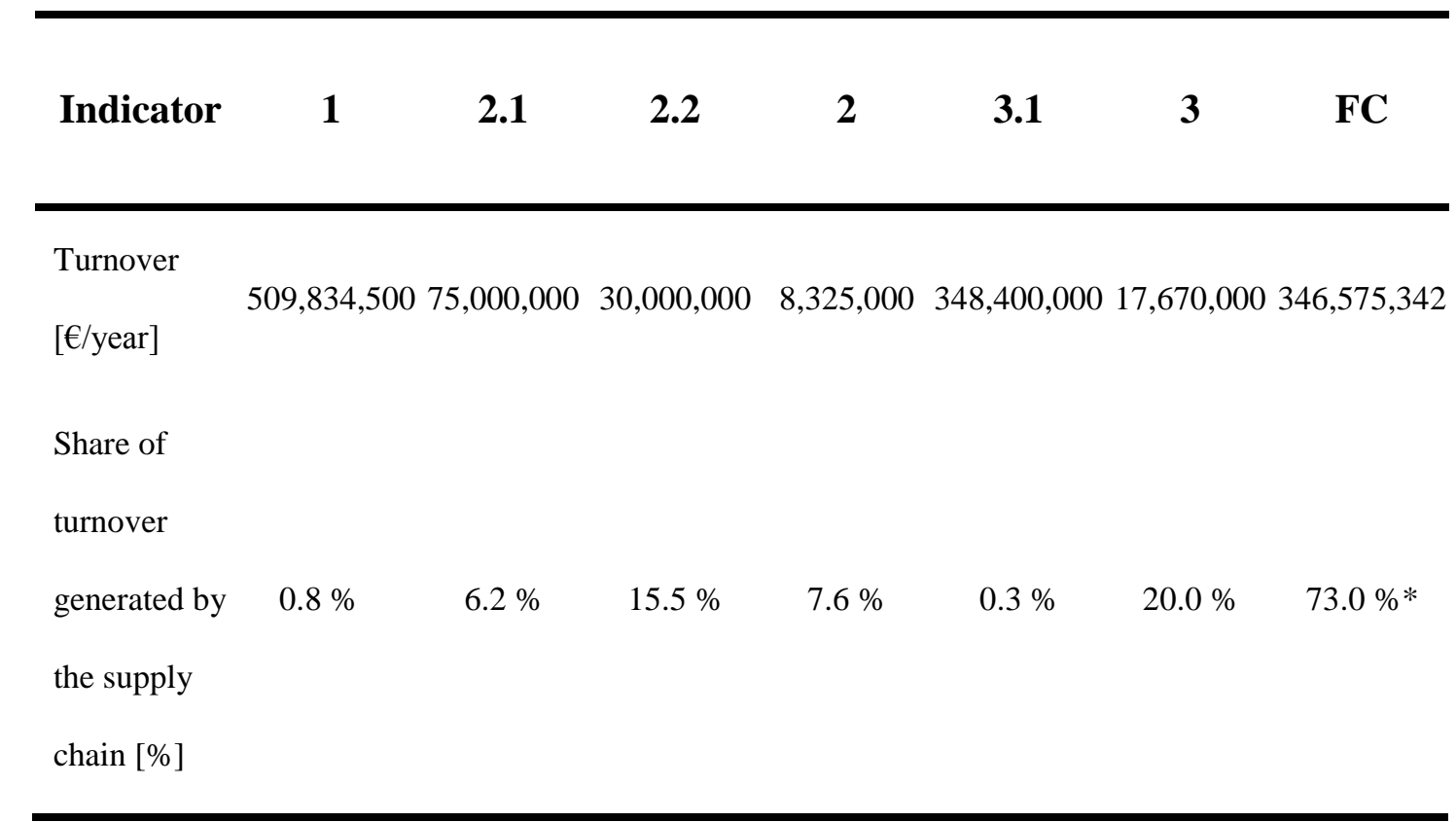

* Value refers to the share of turnover generated by the entire product and not only by the sub-system of the product under analysis in the case study; the sub-system under analysis accounts for one-third of this value; 
Finally, a last round of data collection was performed once the application of the method in the supply chain was complete. A semi-structured interview with the supply chain manager of $F C$ served the purpose to evaluate the numerical results arising from the case study and assess the method.

\section{Data processing}

The decision to focus on a specific sub-system of the final product combined with a partial accessibility to the upstream supply chain for the selected sub-system required some adjustment of raw data obtained from companies in order to achieve a meaningful implementation of the method. These adjustments were required for two reasons.

Sub-system of the final product. The supply chain of a sub-system of the final product is assessed: the economic data of the focal company need to be processed to consider this in order to avoid an over-allocation of the focal company's environmental impact to the product supply chain under analysis in the case study. The sub-system investigated in this work accounts for one third of the value and of the weight of the final product according to the information provided by the focal company, therefore it was necessary to divide the monetary values provided by a factor of 3 . The turnover generated by the sub-system under analysis at $F C$ is thus one third of the turnover generated at $F C$ by the entire engine.

Incomplete upstream supply chain availability for the sub-system. The focal company adopts a parallel- or multiple-sourcing procurement strategy. Only for the engine block intermediate product, two alternative suppliers were accessed, whereas for all other intermediate products a single supplier was accessed for the study. Figure 3 detailed the yearly quantities of the intermediate products and the final product of the supply chain, showing that the yearly quantities differ among the different supply chain links. $F C$ produced yearly 100 units of the 'Engine', while its $1^{\text {st }}$ tier suppliers shipped 
to $F C$ during the same time period intermediate products in the range of 18 (supplier 1 to $F C$ ) to 47 units (supplier 3 to $F C$ ). Since all intermediate products in the part of the supply chain under analysis are supplied to the focal firm in a 1:1 ratio to the final product according to the bill of materials, adopting raw data without any further adjustment would have led to a misalignment between different supply chain members due to different quantities of intermediate products produced, with implications on the environmental performance results. This urged the development of a fictitious supply chain along the real supply chain depicted in Figure 2 and Figure 3 in order to define a common 100-units reference base across the entire supply chain. The development of a supply chain with a common reference base enables to obtain results that are not affected by the yearly quantities produced and facilitates comparisons across different supply chain members. The 100-units reference base was selected, to match the yearly production of the final product by the focal company. The 100-units reference base supply chain was built through system expansion (Bloemhof and Walther 2016), which allows maintaining the absolute and relative performance of each supply chain member unchanged and does not affect the recursive mechanism logic. 


\section{Investigated supply chain}

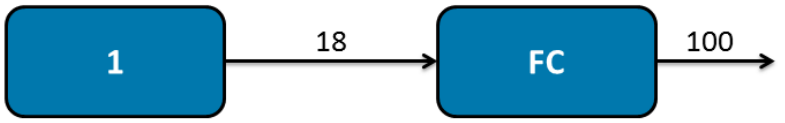

100-units reference base supply chain

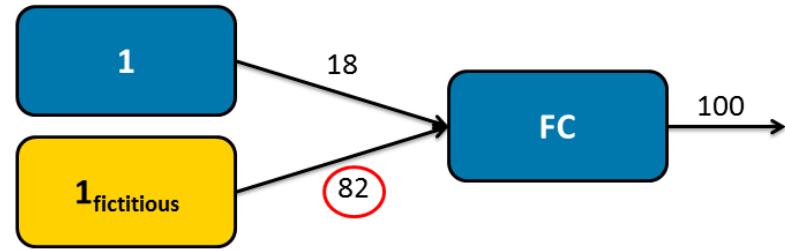

Actual supply chain members

Fictitious supply chain members

Figure 4. Example of building the 100-units reference base supply chain

System expansion is realised by adding a fictitious supply chain member to cover the remaining amount of supply of the intermediate products. As an example, supplier 1 ships 18 crankshaft units to $F C$, therefore supplier $l_{\text {fictitious }}$ is introduced to cover the remaining 82 crankshaft units necessary to produce 100 units of the final product, as shown in Figure 4 . The features of supplier $1_{\text {fictitious }}$ are proportional to those of supplier 1 , both in terms of the environmental performance $E P_{e, i}$ of company $i$ for each specific environmental indicator $e$ (Equation 1) and in terms of the economic performance, represented by the turnover $T_{i}$ of organisation $i$ (Equation 2), where $u$ is the number of yearly units produced by company $i$. Same applies to environmental impact of transport $E P_{e, i, j}^{t r}$ from supplier $j$ to customer $i$ for each environmental indicator $e$ (Equation 3, 4, 5), as the weight is assumed proportional with the units, while the distance is assumed to be the same in the actual and in the fictitious supply chain. This applies both in the case that supplier and customer of each dyad are 
fictitious and in the case where only one of the two organisations is fictitious whereas the other is an actual one.

$$
\begin{aligned}
& E P_{e, i-f i c t i t i o u s}=\frac{E P_{e, i}}{u}(100-u) \\
& T_{i-f i c t i t i o u s}=\frac{T_{i}}{u}(100-u) \\
& E P_{e, j-\text { fictitious }, i}^{t r}=\frac{E P_{e, j, i}^{t r}}{u}(100-u) \\
& E P_{e, j, i-f i c t i t i o u s}^{t r}=\frac{E P_{e, j, i}^{t r}}{u}(100-u) \\
& E P_{e, j-\text { fictitious }, i-f i c t i t i o u s}^{t r}=\frac{E P_{e, j, i}^{t r}}{u}(100-u)
\end{aligned}
$$

Once the process was concluded, the 100-units reference base supply chain was complete (Figure 5). Rectangles in blue colour represent the supply chain members, as shown in Figure 2, whereas the yellow rectangles represent the fictitious supply chain members. The numbers next to each arrow represent the units of intermediate products moved within each dyad in the developed supply chain. 


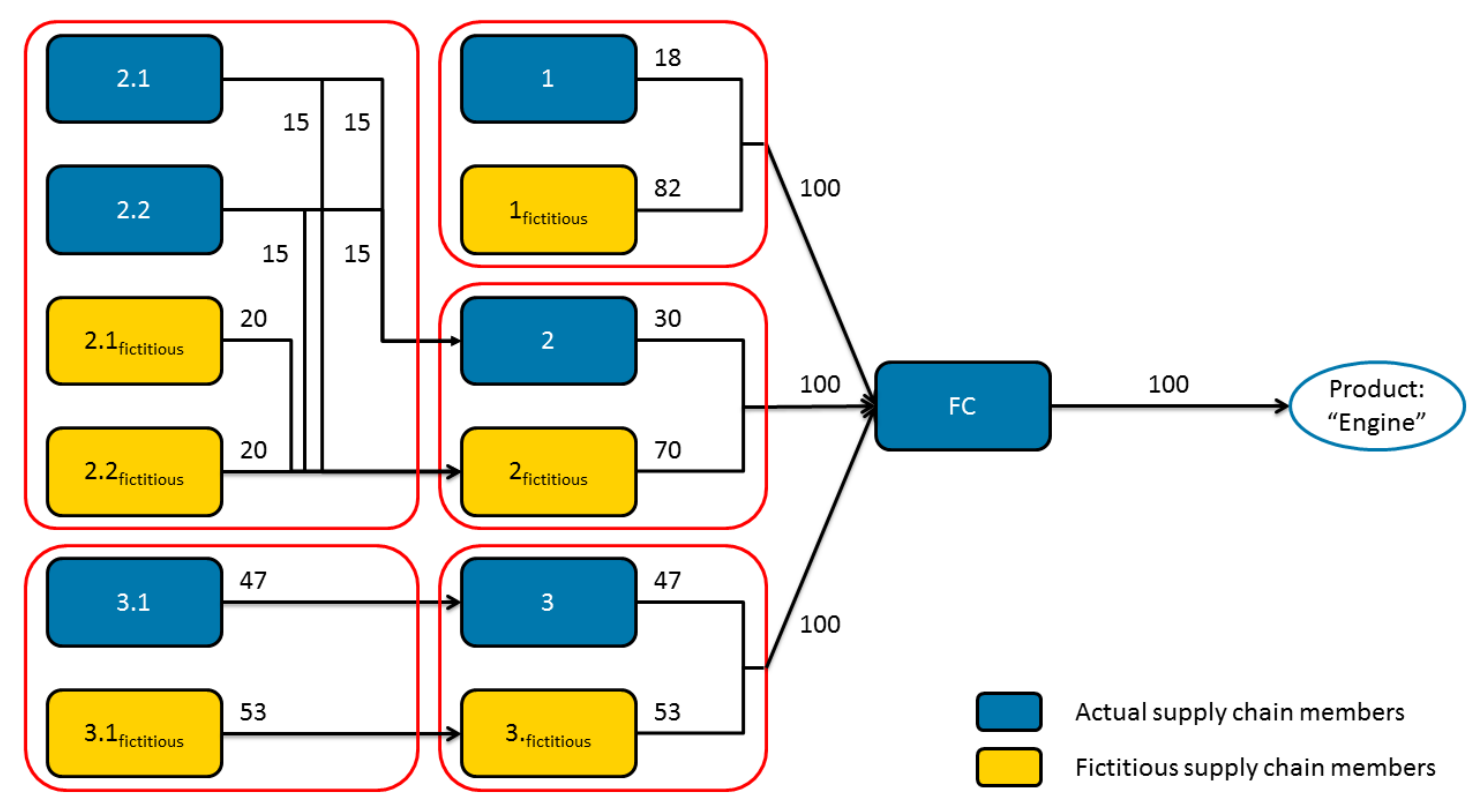

Figure 5. Supply chain including fictitious organisations

\section{Summary of the sustainability performance assessment method}

The performance assessment method adopted in the case study is based on the method presented in Tuni and Rentizelas (2018), which is shaped around five conceptual pillars to model the sustainability performance of the supply chain as well as its structure and dynamics: eco-intensity; cradle-to-gate and transformed resources system boundaries; black-box approach; indirect multi-tier supply chain management approach; transport.

- Eco-intensity: sustainability performance is conceptualised in the method based on eco-intensity, which is defined as the "environmental impact per unit of production value" (Huppes and Ishikawa 2005), thus being the 'use of nature' divided by the economic benefit generated by an economic activity and the reverse of the eco-efficiency concept (Schmidt and Schwegler 2008; European Environment Agency 1999). The social dimension of sustainability is thus outside the scope of this work. Six environmental indicators are adopted at the 
numerator of the ratio. Eco-intensity adopts the economic dimension of sustainability to relate the environmental performance to a single reference unit, integrating two dimensions of sustainability in a single indicator.

- Cradle-to-gate and transformed resources system boundaries: the definition of system boundaries is required to assess the performance of any system (Wiedmann, Lenzen, and Barrett 2009). System boundaries are here defined according to two complementary approaches. Cradle-to-gate approach defines the base boundaries of the supply chain, which includes all activities of the supply chain from raw material extraction (cradle) up to the point where the finished product leaves the organisation (gate) to reach the final customer (Mele et al. 2011; Vasan, Sood, and Pecht 2014; Nasir et al. 2017). The method can be adapted also to gate-to-gate system boundaries, a sub-set of cradle-to-gate approach, in the case of limitations in the access to lower upstream suppliers, as in the case study illustrated in this work. Transformed resources approach defines the side boundaries of the supply chain, taking into consideration only "product-related suppliers" dealing with resources that will be treated, transformed or converted during the production processes and end up into the final product (Kovács 2008; Slack, Brandon-Jones, and Johnston 2013). As such, the domain of use of the method is limited to supply chains offering a physical product as the final product.

- Black-box approach: on top of conceptualising the boundaries of the system under analysis, the definition of the level of granularity, i.e. the elementary subsystem into which the system is decomposed, is also required to conceptualise the system and understand its complexity (Low et al. 2015). The connected and independent organisations part of the supply chain are considered in this work as 
the elementary sub-systems (Mena, Humphries, and Choi 2013; Christopher 2011; Koh, Gunasekaran, and Tseng 2012). As such, each organisation is treated as black box and the only aspect considered is the "global relationship between the inputs and the outputs of the system", while the internal dynamics of each company remain outside the scope of the work (Oberkampf and Roy 2010). The black box approach is applied consistently to the environmental and economic dimension of each organisation part of the supply chain, thus limiting the information required to be collected at each company to a limited set of environmental and economic inputs and outputs.

- Indirect multi-tier supply chain management approach: the indirect approach is formalised in the method into an information-sharing mechanism (Tachizawa and Wong 2014), which works along two directions, going upstream and downstream. On one hand, focal firms require their $1^{\text {st }}$ tier suppliers to spread sustainability requirements to lower-tier suppliers and to obtain relevant information about their sustainable behaviour (Tachizawa and Wong 2014). On the other hand, the requested requirements are forwarded downstream to the focal company thanks to an iterative process, materialised through a recursive mechanism.

- Transport: the inclusion of the environmental performance of the transport between the different supply chain tiers is an addition of the current work to the method presented in Tuni and Rentizelas (2018). Products being transported are only spatially transformed, but do not undergo any further transformation in their physical nature. As a result, transport is not treated according to the black box approach as a separate tier within the supply chain, because there are no transformed resources entering the supply chain at the transport stage. However, 
the environmental impact of the spatial transformation cannot be neglected in a SSCM perspective (Azadi et al. 2015) and needs to be incorporated within the method. This is conceptually modelled by capturing the point of origin and the point of destination in each dyadic transport link, expressed as geographical locations. Moreover, the key features of this spatial transformation affecting the environmental impact of transport are also captured, which are the mode of transport and the weight of goods moved, as the environmental impact of transport "depend on ton-miles and the mode of transportation" (Bouchery et al. 2012; Sundarakani et al. 2010; Kannegiesser and Günther 2013). Only two environmental categories are impacted by transport activities, which are 'Energy consumption' and 'Emissions to air', in line with Harris et al. (2011). The environmental impact of transport activities with respect to these two indicators is calculated using EcoTransIT online tool, which has already been used in the SSCM literature, like in Brandenburg (2015). EcoTransIT follows the "Methodology for calculation and declaration of energy consumption and GHG emissions of transport services (freight and passengers)", adopting factors per distance unit and weight unit to estimate the environmental impact of transport (EcoTransIT World Initiative 2016; Soysal, Bloemhof-Ruwaard, and Van Der Vorst 2014). The indicators are calculated according to the tank-to-wheel option (TTW) in accordance with the transformed resources system boundary adopted in this work and a separate calculation is performed for each transport activity taking place between any two supply chain organisations.

The five conceptual pillars were transformed into relevant mathematical formulations to allow the calculations of the eco-intensity results at the company level and at the supply chain level, as well as to calculate the absolute environmental impact 
associated to the final product, here referred to as the environmental backpack.

Calculations are performed in accordance with the mathematical model presented in Tuni and Rentizelas (2018) and follow the steps identified in the flowchart represented in Figure 6.

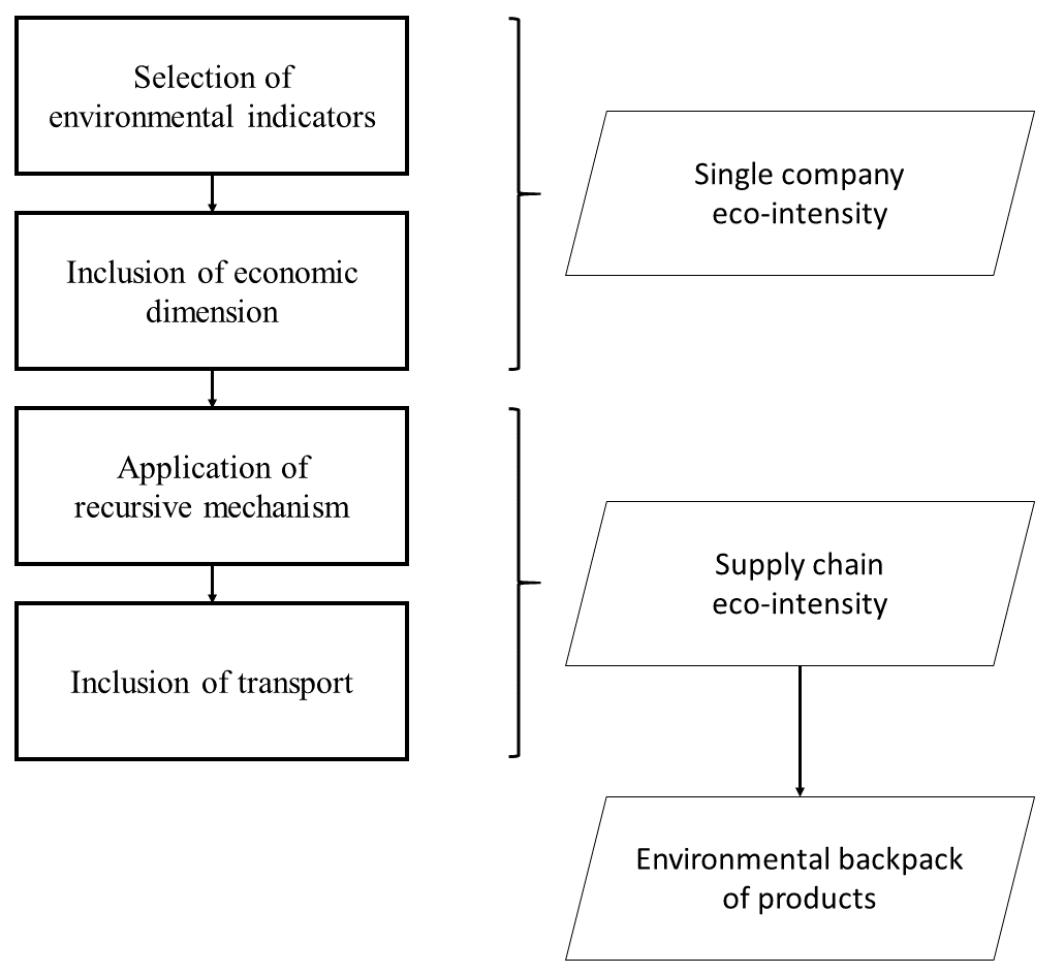

Figure 6. Method flowchart

\section{Results}

The application of the method in the case study generated three main outputs, which are presented in this section: the eco-intensity indicators at the company level (Table 4), the eco-intensity indicators at the supply chain level (Table 5) and the environmental impact allocated to the final product (Table 6), which is calculated starting from the eco-intensity indicators at the supply chain level, and is here referred as the environmental backpack associated to one unit of engine. Additionally, two applications of the method arising from the outputs are also outlined in this section, which are the 
supplier selection and evaluation and the hotspot identification.

\section{Single company eco-intensity indicators}

Table 4 introduces the eco-intensity indicators at the company level. Since the fictitious supply chain members' environmental and economic performances are proportional to those of the equivalent supply chain members, the relative indicators, such as ecointensity indicators, are the same for both the fictitious and the actual organisations. Therefore, only the eco-intensity indicators of the actual companies are presented. Although companies' core businesses differ, an initial analysis of the values presented in Table 4 demonstrates that the $2^{\text {nd }}$ tier supplier 3.1 shows the worst ecointensity in three out of six environmental impact areas (material consumption, land occupation and water consumption). Particularly in the case of material consumption, the eco-intensity of supplier 3.1 is several orders of magnitude greater compared to that of other companies belonging to the supply chain. As supplier 3.1 converts raw material into steel, the consumption of raw materials is naturally very significant, as depicted by the findings. The $1^{\text {st }}$ tier supplier 1 performs worst in two environmental categories (energy consumption and emissions to air), whereas $F C$ is imputable for the worst performance in terms of solid waste. The findings of the case study confirm the need to extend the assessment of the supply chain beyond $1^{\text {st }}$ tier suppliers to achieve a holistic view of the supply chain sustainability performance, as the biggest environmental impact per unit of value generated is found at the $2^{\text {nd }}$ tier supplier for half of the environmental categories. Finally, it is interesting to notice that supplier 2 performs best in all four environmental input categories, which reflects its role as an outsourcing organisation at the edge between manufacturing and servicing, with limited inputs incoming into the company. 
Table 4. Single company eco-intensity indicators

\begin{tabular}{|c|c|c|c|c|c|c|c|c|}
\hline \multirow{2}{*}{\multicolumn{2}{|c|}{ Eco-intensity indicators }} & \multicolumn{7}{|c|}{ Eco-intensity performance } \\
\hline & & 1 & 2.1 & 2.2 & 2 & 3.1 & 3 & $\mathrm{FC}$ \\
\hline $\begin{array}{l}\text { Material } \\
\text { consumption }\end{array}$ & {$[\mathrm{kg} / €]$} & 2.595 & 0.906 & 0.030 & 0.000 & 14.551 & 0.508 & 0.081 \\
\hline $\begin{array}{l}\text { Land } \\
\text { occupation }\end{array}$ & {$\left[\mathrm{m}^{2} / €\right]$} & 0.005 & 0.001 & 0.001 & 0.001 & 0.015 & 0.005 & 0.002 \\
\hline $\begin{array}{l}\text { Water } \\
\text { consumption }\end{array}$ & {$\left[\mathrm{m}^{3} / €\right]$} & 0.002 & 0.001 & 0.001 & 0.000 & 0.490 & 0.000 & 0.001 \\
\hline $\begin{array}{l}\text { Energy } \\
\text { consumption }\end{array}$ & {$[\mathrm{kWh} / €]$} & 2.748 & 0.897 & 1.081 & 0.175 & 1.565 & 0.651 & 0.391 \\
\hline $\begin{array}{l}\text { Emissions } \\
\text { to air }\end{array}$ & {$\left[\mathrm{kg} \mathrm{CO}_{2} \mathrm{e} / €\right]$} & 3.103 & 0.897 & 1.125 & 0.162 & 0.712 & 0.344 & 0.141 \\
\hline $\begin{array}{l}\text { Solid } \\
\text { waste }\end{array}$ & {$[\mathrm{kg} / €]$} & 0.382 & 0.000 & 0.062 & 0.065 & 0.312 & 0.150 & 2.866 \\
\hline
\end{tabular}

\section{Supply chain eco-intensity indicators}

The supply chain results, listed in Table 5, numerate the eco-intensity indicators for the 100-units reference base supply chain that includes fictitious supply chain members. This choice avoids potential bias in the results due to different values in the number of produced units at different supply chain members.

The values in Table 5 represent the eco-intensity of the multi-tier supply chain with respect to each environmental impact and are the main output of the assessment of the supply chain sustainability performance. A comparison between the values of different eco-intensity indicators is not meaningful as different units of measurement are used to calculate the environmental numerator of the indicator. However, the last column of the table points out the difference between the eco-intensity values at the supply chain level compared to the focal company eco-intensity values as an 
autonomous entity without the environmental impact associated with the supply chain.

The values demonstrate that the eco-intensity would be significantly underestimated had the supply chain not been considered, potentially misleading managers on the environmental impact areas to tackle. The values show that the supply chain ecointensity can be over ten times higher than the focal company's eco-intensity in some instances, like in the case of material consumption and water consumption environmental categories. The raw material and water required to produce steel at $2^{\text {nd }}$ tier supplier 3.1 contribute significantly to these results, which are then cascaded along the supply chain. The only indicator that is not affected by adopting a supply chain perspective is the solid waste eco-intensity, with a very limited variation between the supply chain eco-intensity and the focal company eco-intensity. As observed already in Table 4, $F C$ was identified as the worst performing organisation in this category, anticipating the limited deviation of the supply chain score from the focal firm's one.

Table 5. Supply chain eco-intensity indicators

\begin{tabular}{llcc}
\hline \multicolumn{1}{c}{$\begin{array}{c}\text { Product: } \\
\text { 'Engine' }\end{array}$} & \multicolumn{1}{c}{$\begin{array}{c}\text { Supply chain } \\
\text { eco-intensity }\end{array}$} & $\begin{array}{c}\text { Difference compared to the } \\
\text { focal company } \\
\text { eco-intensity without } \\
\text { environmental backpack }\end{array}$ \\
\hline Material consumption & {$[\mathrm{kg} / €]$} & 1.292 & $1,487 \%$ \\
Land occupation & {$\left[\mathrm{m}^{2} / €\right]$} & 0.004 & $156 \%$ \\
Water consumption & {$\left[\mathrm{m}^{3} / €\right]$} & 0.016 & $1,443 \%$ \\
Energy consumption & {$[\mathrm{kWh} / €]$} & 1.449 & $270 \%$ \\
Emissions to air & {$[\mathrm{kg} \mathrm{CO} 2 \mathrm{e} / €]$} & 1.197 & $747 \%$ \\
Solid waste & {$[\mathrm{kg} / €]$} & 2.994 & $4 \%$ \\
\hline
\end{tabular}

\section{Environmental backpack of products}

Finally, the environmental backpack associated to the product was calculated (Table 6). 
Once again, the values refer to the 100-units reference base supply chain. The environmental backpack was calculated both for the entire yearly production of the final product and for one unit of the engine, which is the typical unit the final product is priced at, thus introducing an alternative reference unit for the environmental impact.

Table 6. Environmental backpack associated to the final product

\begin{tabular}{|c|c|c|c|c|}
\hline \multirow{2}{*}{$\begin{array}{r}\begin{array}{r}\text { Product: } \\
\text { 'Engine' }\end{array} \\
\text { Material } \\
\text { consumption }\end{array}$} & \multicolumn{2}{|c|}{$\begin{array}{l}\text { Overall environmental } \\
\text { backpack per year }\end{array}$} & \multicolumn{2}{|c|}{$\begin{array}{c}\text { Environmental backpack } \\
\text { per engine unit }\end{array}$} \\
\hline & [kg/year] & $108,987,007$ & [kg/unit] & $1,089,870$ \\
\hline $\begin{array}{l}\text { Land } \\
\text { occupation }\end{array}$ & {$\left[\mathrm{m}^{2} /\right.$ year $]$} & 348,190 & {$\left[\mathrm{~m}^{2} /\right.$ unit $]$} & 3,482 \\
\hline $\begin{array}{l}\text { Water } \\
\text { consumption }\end{array}$ & {$\left[\mathrm{m}^{3} /\right.$ year $]$} & $1,321,281$ & {$\left[\mathrm{~m}^{3} /\right.$ unit $]$} & 13,213 \\
\hline $\begin{array}{l}\text { Energy } \\
\text { consumption }\end{array}$ & {$[\mathrm{kWh} /$ year $]$} & $122,226,841$ & [kWh/unit] & $1,222,268$ \\
\hline $\begin{array}{l}\text { Emissions } \\
\text { to air }\end{array}$ & {$\left[\mathrm{kg} \mathrm{CO}_{2}\right.$ e/year $]$} & $100,947,048$ & {$\left[\mathrm{~kg} \mathrm{CO}_{2}\right.$ e/unit $]$} & $1,009,470$ \\
\hline $\begin{array}{l}\text { Solid } \\
\text { waste }\end{array}$ & [kg/year] & $252,495,060$ & [kg/unit] & $2,524,951$ \\
\hline
\end{tabular}

A quota of the overall energy consumption and emissions to air is due to the impact of transport. However, the contribution of transport towards the overall environmental backpack in the case study, i.e. the sum of the environmental impacts associated to all dyadic transport activities within the supply chain, is limited compared to the impact of supply chain members. Transport accounts for $51,964 \mathrm{kWh} / \mathrm{unit}$ and $13,142 \mathrm{~kg} \mathrm{CO}_{2}$ e/unit, which represent $4 \%$ and $1 \%$ of the overall environmental impact imputable to the supply chain respectively. Despite being an international supply chain with long distance transport required, the supply chain under analysis includes some very energy-intensive and carbon-intensive production activities, such as forging, 
casting and steelmaking, which take on the biggest share of the environmental impact in these categories.

Figure 7 details the environmental backpack by identifying the relative contribution of each supply chain member towards the supply chain total. Given the minimal contribution of transport towards the overall supply chain environmental impact, impacts arising from each transportation link were merged with the impacts of the upstream tier involved in each transportation link in the figure.

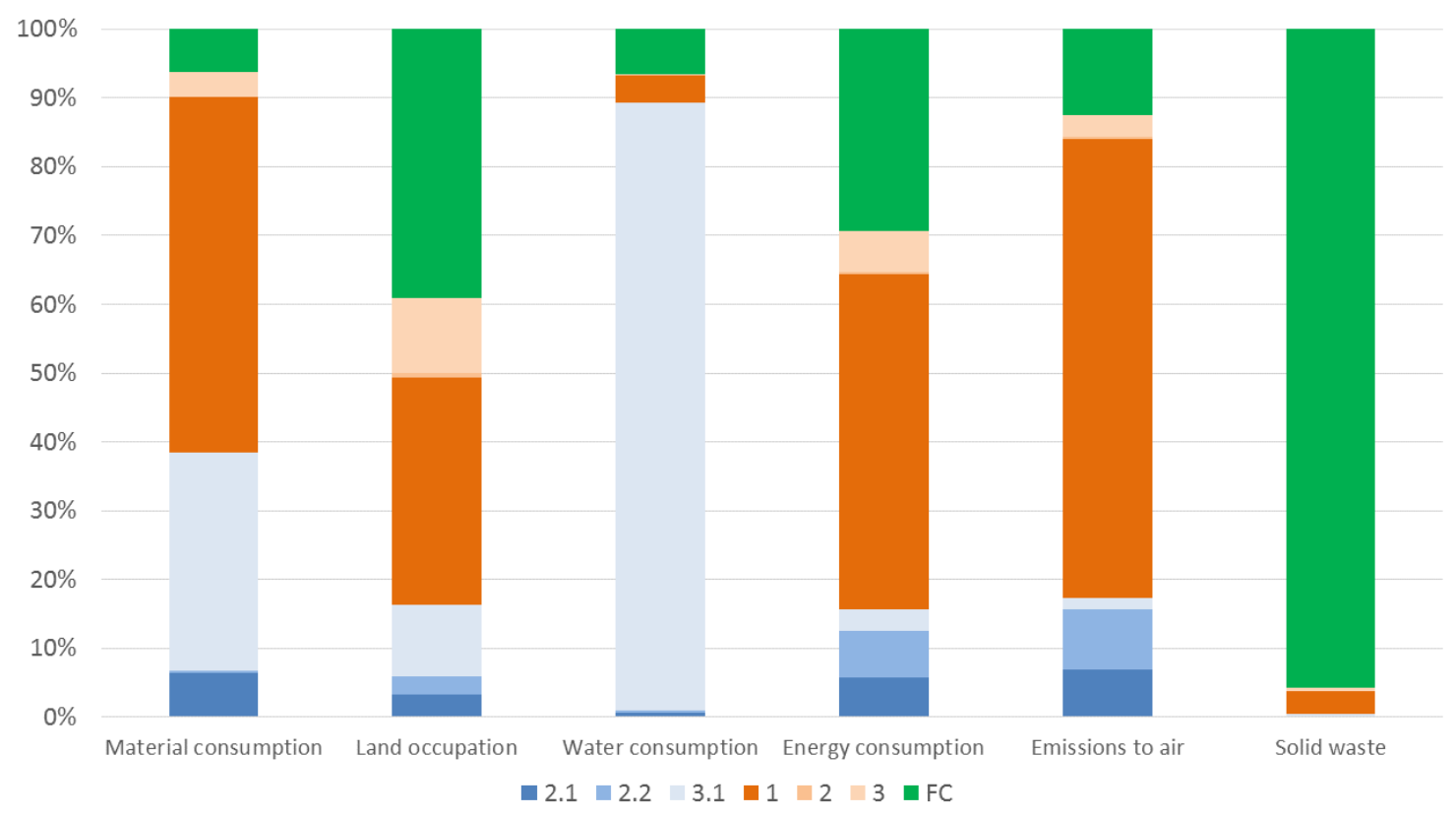

Figure 7. Environmental backpack breakdown by supply chain member

The environmental backpack of some environmental categories is completely dominated by one company: $F C$ is responsible for the over $90 \%$ of the overall waste generated throughout the product supply chain, whereas 3.1 is responsible for the majority of water consumption. In addition, emissions to air environmental backpack is largely imputable to a single organisation, with supplier 1 being accountable for over $60 \%$ of them. On the other hand, other environmental categories show a more balanced 
pattern in terms of absolute environmental impact through the supply chain members. This is the case especially for land occupation, where no single organisation contributes for more than $40 \%$ of the supply chain environmental backpack.

While the eco-intensity results show the relative performance of each supply chain member, the environmental backpack breakdown (Figure 7) highlights the absolute environmental impact contribution allocated to each supply chain member for the product under analysis, thus providing an additional piece of information. The absolute values are affected by the annual turnover each company generates through the supply chain. This is particularly evident in the case of material consumption, where supplier 1 contributes to almost $50 \%$ of the overall absolute consumption while 3.1 is accountable for $32 \%$ in absolute values, despite their eco-intensity indicators being respectively $2.595 \mathrm{~kg} / €$ and $14.551 \mathrm{~kg} / €$.

\section{Supplier evaluation}

The method is able to support supply chain managers in the evaluation of alternative suppliers. This is performed in the case study by evaluating two active parallel suppliers (2.1 and 2.2), however the application can be potentially extended to tentative suppliers as part of the supplier selection process. Both organisations 2.1 and 2.2 supply the engine block to the focal company, which is machined by outsourcer 2 before reaching the focal company. The core business of both companies is casting, and the products offered to the market are also comparable.

The numerical results of the two parallel suppliers were originally presented in Table 4 and are recalled for benchmarking purposes in Table 7. The scores only take into account the internal performance of the suppliers and do not consider any contribution from the supply chain, as no suppliers of 2.1 and 2.2 were involved in the case study. The two companies show comparable performance in terms of two eco- 
intensity indicators (land occupation and water consumption), which however take on limited importance for companies involved in casting operations. On the other hand, since casting is an energy-intensive industry, a greater attention is paid to energy consumption eco-intensity and emissions to air eco-intensity with the latter largely emanating from energy consumption. For both eco-intensity indicators, 2.1 performs better than 2.2, with an improved performance of $17 \%$ and $20 \%$ respectively. Supplier 2.1 also scores significantly better in terms of solid waste eco-intensity, as the company barely generates any waste. The situation flips over if the material consumption ecointensity is considered: in this case, the consumption of 2.2 is very limited which is reflected in a lower eco-intensity score.

However, in order to effectively compare the overall performance of the two parallel suppliers, an aggregated index is required to provide comprehensive information about the behaviour of the suppliers (Zhou et al. 2012). Therefore, normalisation, weighting and aggregation of the indicators are required to obtain an aggregated eco-intensity index (Salvado et al. 2015; Zhou et al. 2012).

Normalisation can be performed by comparing different "alternatives with respect to specific aspects" (Tugnoli, Santarelli, and Cozzani 2008), which are in this case the eco-intensity indicators. This approach, also known as internal normalisation, is suitable when the alternatives are comparable in nature (Tugnoli, Santarelli, and Cozzani 2008), a requisite met in this instance as the parallel suppliers belong to the same industry with comparable products offered to the market. Normalisation is achieved by dividing the eco-intensity indicator $E I_{e, i}$ of each supplier $i$ with respect to environmental category $e$ by the sum of the eco-intensity indicators of the $z$ suppliers being benchmarked for each environmental indicator $e$ (Tsoulfas and Pappis 2008; 
Mahdiloo, Saen, and Lee 2015), thus respecting the unit-invariance of indicators (Equation 6).

$$
E I_{e, i, n}=\frac{E I_{e, i}}{\sum_{i}^{z} E I_{e, i}}
$$

The normalised eco-intensity indicators of suppliers 2.1 and 2.2 are also displayed in Table 7, highlighting in green the more environmentally sustainable supplier and in red the more eco-intense supplier for each environmental category.

The weighting step was accomplished through equal weighting as it generates "results nearly as good as those optimal weighting methods" (Wang et al. 2009), while requiring limited knowledge and input from decision makers. Finally, the normalised eco-intensity indicators are aggregated according to linear aggregation (Salvado et al. 2015). The total eco-intensity of the parallel suppliers is calculated by adding the normalised score in an aggregated index as it appears at the bottom line of Table 7 . The aggregated eco-intensity scores show that the suppliers are very close in terms of overall sustainability performance; however, supplier 2.2 has a small edge, performing $5 \%$ better than supplier 2.1, with an overall eco-intensity score of 2.934 .

The follow-up interview with the supply chain manager of $F C$ confirmed the validity of the comparative results of parallel suppliers 2.1 and 2.2, as the outcomes accurately represent the different technological solutions and production processes adopted. The different preparation of moulding boxes allows 2.2 to internally recycle a high share of the metal sward and to use lower quantities of material to produce the same products, resulting in reduced material consumption, a result that is confirmed by the findings of the case study. On the other hand, 2.1 outscores supplier 2.2 in the key environmental indicator for casting industry, which is the energy consumption. 
Organisation 2.2 adopts a more energy-intensive production process due to the adopted casting technologies, which requires more time in the foundry for the produced casts, also leading to a higher value of emissions to air eco-intensity, due to the less technologically advanced production process.

Table 7. Normalised eco-intensity scores of parallel suppliers

\begin{tabular}{|c|c|c|c|c|c|}
\hline \multirow{2}{*}{$\begin{array}{l}\text { Eco-intensity } \\
\text { indicator } \\
\text { (at the } \\
\text { company } \\
\text { level) }\end{array}$} & \multicolumn{3}{|c|}{2.1} & \multicolumn{2}{|c|}{2.2} \\
\hline & Ecc & -intensity & $\begin{array}{l}\text { Normalised } \\
\text { eco-intensity }\end{array}$ & Eco-intensity & $\begin{array}{l}\text { Normalised } \\
\text { eco-intensity }\end{array}$ \\
\hline $\begin{array}{l}\text { Material } \\
\text { consumption }\end{array}$ & 0.906 & $\mathrm{~kg} / €$ & 0.968 & $0.030 \mathrm{~kg} / €$ & 0.032 \\
\hline $\begin{array}{l}\text { Land } \\
\text { occupation }\end{array}$ & 0.001 & $\mathrm{~m}^{2} / €$ & 0.550 & $0.001 \mathrm{~m}^{2} / €$ & 0.450 \\
\hline $\begin{array}{l}\text { Water } \\
\text { consumption }\end{array}$ & 0.001 & $\mathrm{~m}^{3} / €$ & 0.645 & $0.001 \mathrm{~m}^{3} / €$ & 0.355 \\
\hline $\begin{array}{l}\text { Energy } \\
\text { consumption }\end{array}$ & 0.897 & $\mathrm{kWh} / €$ & 0.454 & $1.081 \mathrm{kWh} / €$ & 0.546 \\
\hline $\begin{array}{l}\text { Emissions } \\
\text { to air }\end{array}$ & 0.897 & $\mathrm{kgCO}_{2} \mathrm{e} / €$ & 0.444 & $1.125 \mathrm{kgCO}_{2} \mathrm{e} / €$ & 0.556 \\
\hline $\begin{array}{l}\text { Solid } \\
\text { waste }\end{array}$ & 0.000 & $\mathrm{~kg} / €$ & 0.006 & $0.062 \mathrm{~kg} / €$ & 0.994 \\
\hline Total & & & 3.066 & & 2.934 \\
\hline
\end{tabular}

\section{Hotspot identification}

The recursive mechanism adopted by the method is functional to identify eco-intensity hotspots along the supply chain. This is performed through an iterative process that aims to identify the supply chain branches and organisations with the highest ecointensity in order to prioritise action through internal operational improvement at the companies where the environmental impact per value generated is the highest. While the eco-intensity indicators are cascaded downstream along the supply chain, the 
recognition of the hotspots follows a recursive logic going in the opposite direction, moving upstream from the focal company and tracing back the least environmentally sustainable company per each indicator. A different number of iterations is required to reach the hotspot, as the focal company does not have visibility of suppliers beyond tier1, as detailed in Figure 8, Figure 9 and Figure 10, where the hotspot identification path is highlighted in a blue dotted line. In the same figures, companies are represented in a relative colour scale. At each iteration, the organisation involved in the process (depicted with bold outline), is represented according to its internal eco-intensity without environmental backpack, whereas its suppliers are represented according to their eco-intensity including the environmental backpack associated to their upstream supply chain, which is the actual value that is passed by each supply chain member to the next one. The eco-intensity is recalculated in a similar manner for each subsequent iteration at lower tier levels, as per the example of Figure 8.

The case study highlights three different examples of positioning of the hotspots, with a different number of iteration stages required to identify the supply chain hotspots. Two iterations are required to identify the hotspots of material consumption, land occupation and water consumption eco-intensity. In all these instances the hotspot is located at the $2^{\text {nd }}$ tier supplier 3.1 . However, in all these cases, the focal company does not have a direct visibility of the poor environmental performance of supplier 3.1, but recognises instead supplier 3 as the most eco-intense organisation among its $1^{\text {st }}$ tier suppliers, as the example for water consumption shows in Figure 8. This is achieved at the first iteration by comparing its internal eco-intensity excluding backpack with the eco-intensity values including backpack passed on by its $1^{\text {st }}$ tier suppliers (Figure 8a) and identifying supplier 3 as the focus for reducing water consumption. Then, it is company 3 that, repeating a similar analysis, performs the second iteration, by 
comparing its own internal water consumption eco-intensity excluding backpack with the eco-intensity value passed on by its supplier 3.1 (Figure $8 \mathrm{~b}$ ). From the second iteration, it is recognised that the hotspot is located at the $2^{\text {nd }}$ tier supplier 3.1 and that the operational improvement for water consumption in the supply chain has thus to be prioritised at $2^{\text {nd }}$ tier supplier 3.1. This constitutes an example of indirect supply chain management approach, as the hotspot is identified at the $2^{\text {nd }}$ tier of the supply chain without $F C$ having direct visibility of its supply chain beyond its direct suppliers.

A similar mechanism is applied for the other environmental categories where the hotspot is located at the $2^{\text {nd }}$ tier supplier 3.1 , such as material consumption and land occupation.

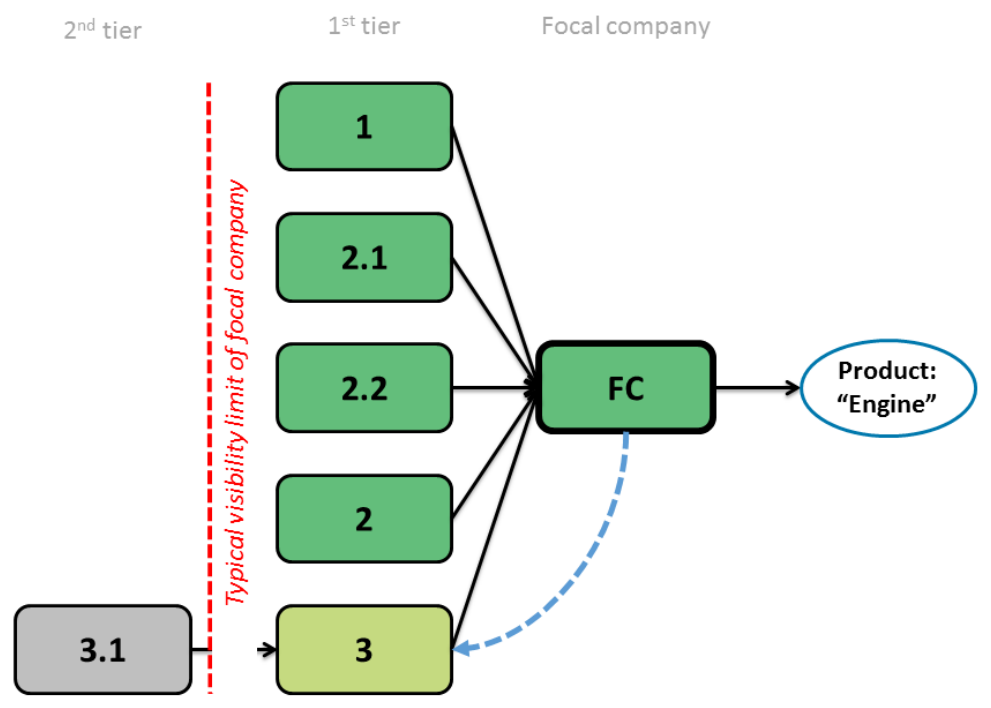




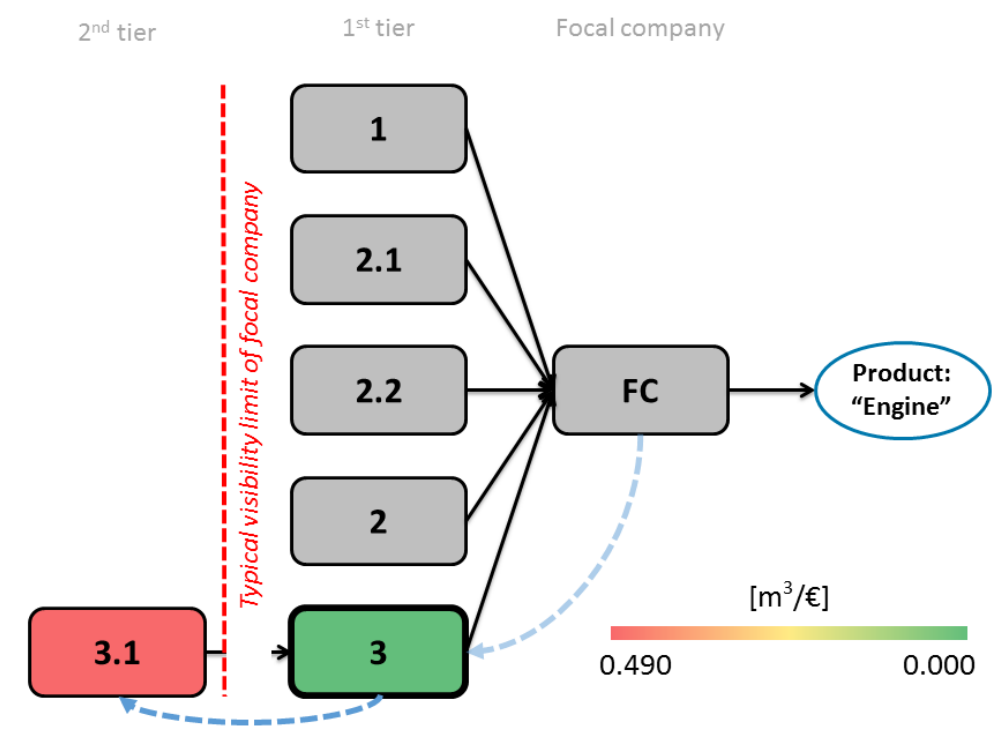

Figure 8. Hotspot identification iterations for water consumption eco-intensity: iteration at the focal company (a) and iteration at $1^{\text {st }}$ tier supplier 3 (b)

On the other hand, only one iteration is required to identify the hotspot for the energy consumption and emissions to air eco-intensity indicators, which are both located at the $1^{\text {st }}$ tier supplier 1 . The example for energy consumption is depicted in Figure 9. In this case, the focal company identifies supplier 1 as the most eco-intense by comparing its internal eco-intensity excluding backpack with the eco-intensity indicators of all its $1^{\text {st }}$ tier suppliers including backpack. The process is not repeated at supplier 1 as there are no lower tier suppliers upstream in that specific supply chain branch. Therefore, hotspot is localised at 1 and operational improvement for energy consumption and emissions to air has to be prioritised at this company. 


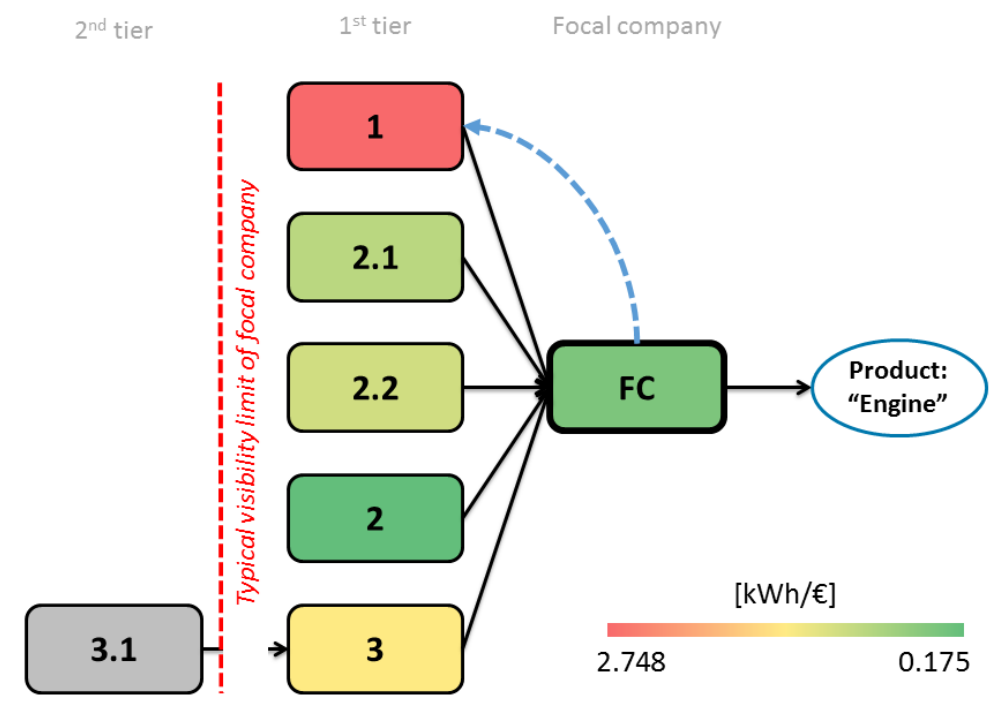

Figure 9. Hotspot identification iteration for energy consumption eco-intensity

Finally, no iteration is required for the solid waste eco-intensity, as the focal company recognizes itself as the hotspot for this environmental impact by comparing its internal eco-intensity performance excluding backpack with the eco-intensity indicators including backpack that are passed on by the $1^{\text {st }}$ tier suppliers (Figure 10). Therefore, operational improvement for solid waste has to be prioritised at the focal company.

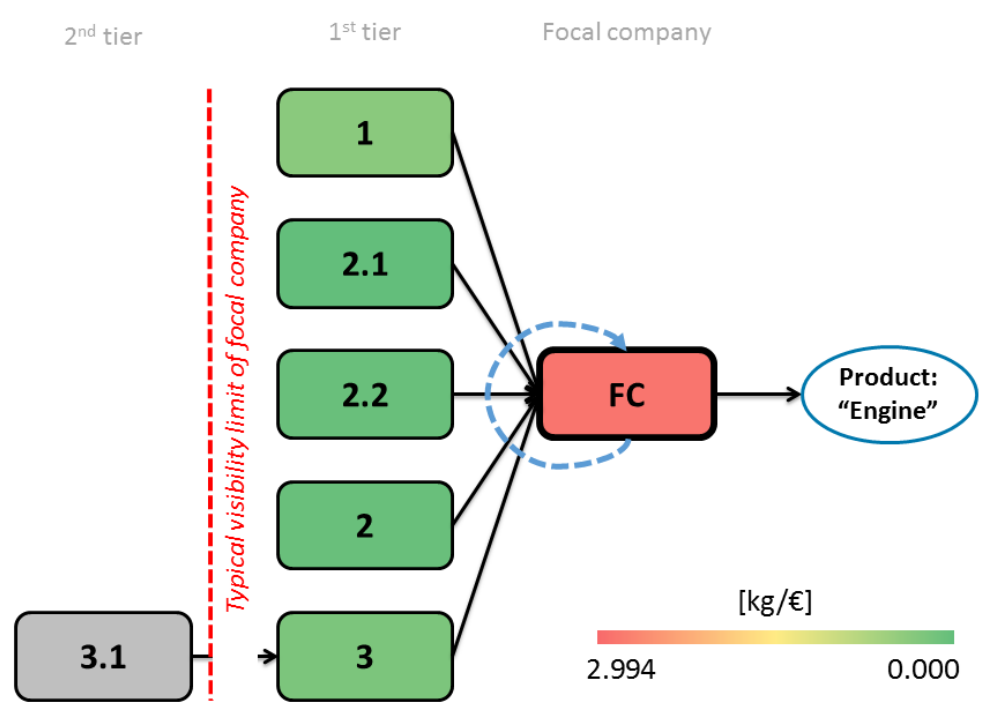


Figure 10. Hotspot identification for solid waste eco-intensity

\section{Discussion}

The application of the eco-intensity method in an operative machinery supply chain highlights a number of implications for practitioners and academics. The former ones are associated with the applicability of the method and its results to support managerial decision-making as well as to the management of sustainability tensions. Additionally, the application of the method provides also insights for theory, both in the area of SSCM tensions and in the area of SSCM performance assessment.

\section{Implications for theory}

\section{Implications for SSCM tensions}

The adoption of an eco-intensity method to assess the sustainability performance of the supply chain constitutes an integrative approach towards environmental and economic sustainability, without prioritising any of the two dimensions (Hahn et al. 2015). The identification of hotspots and the benchmarking of alternative suppliers can serve as the starting point to direct operational improvement actions within the supply chain. The values of the eco-intensity indicators can be lowered and therefore improved through four paths that fall within the instrumental logic, as outlined in Figure 11:

(A) Improvement of the environmental performance, which means maintaining a stable economic performance while lowering the environmental impact for one or more environmental indicators; this improvement path moves along the environmental performance axes at the intersection between the 'win-win' and the 'trade-off with environmental preference' quadrants; 
(B) Improvement of the economic performance, which means maintaining a stable environmental performance while increasing the generated turnover; this improvement path moves along the economic performance axes at the intersection between the 'win-win' and the 'trade-off with economic preference' quadrants;

(C) Simultaneous improvement of the environmental and economic performance: a combination of the two previous strategies, which implies an improvement path anywhere in the 'win-win' quadrant;

(D) Improvement of the economic performance proportionally greater than the worsening of the environmental performance; this improvement path lies anywhere in the orange area within the 'trade-off with economic preference' quadrant;

However, an additional improvement path is offered according to the integrative method proposed in this work, which does not fall within the instrumental logic:

(E) Improvement of the environmental performance proportionally greater than the worsening of the economic performance; this improvement path lies anywhere in the orange area within the 'trade-off with environmental preference' quadrant;

This last option, which is embedded in the concept of weak sustainability and substitutability between the sustainability dimensions, allows clearly distinguishing between the instrumental logic and the integrative logic to address sustainability tensions. While the instrumental perspective prescribes that sustainability should not affect the economic performance (Xiao et al. 2019; Van der Byl and Slawinski 2015), thus limiting the improvement area to the green-bounded rectangle in Figure 11, the 
integrative approach adopted in the method rotates the improvement area by $45^{\circ}$ clockwise, as defined by the red triangle in the figure, without prioritising any sustainability dimension over the other. Therefore, the approach proposed in this work offers an alternative lens through which addressing sustainability tensions can be managed.

Although the weak sustainability perspective has been targeted with criticism due to its substantial anthropocentric perspective towards the environment and its assumptions of virtually infinite natural capital (Mebratu 1998; Costanza and Daly 1992; Hopwood, Mellor, and O’Brien 2005), the eco-intensity application of weak sustainability adopted in this method is functional to overcome tensions between sustainability dimensions by obtaining a balanced evaluation of the environmental and economic dimensions of sustainability. As a result, the method offsets the asymmetry power between the economic element and other elements of sustainability - the environmental dimension in this specific case, avoiding the traditional profit-centric approach currently adopted in sustainable supply chain management (Van der Byl and Slawinski 2015; Montabon, Pagell, and Wu 2016; Matthews et al. 2016). 


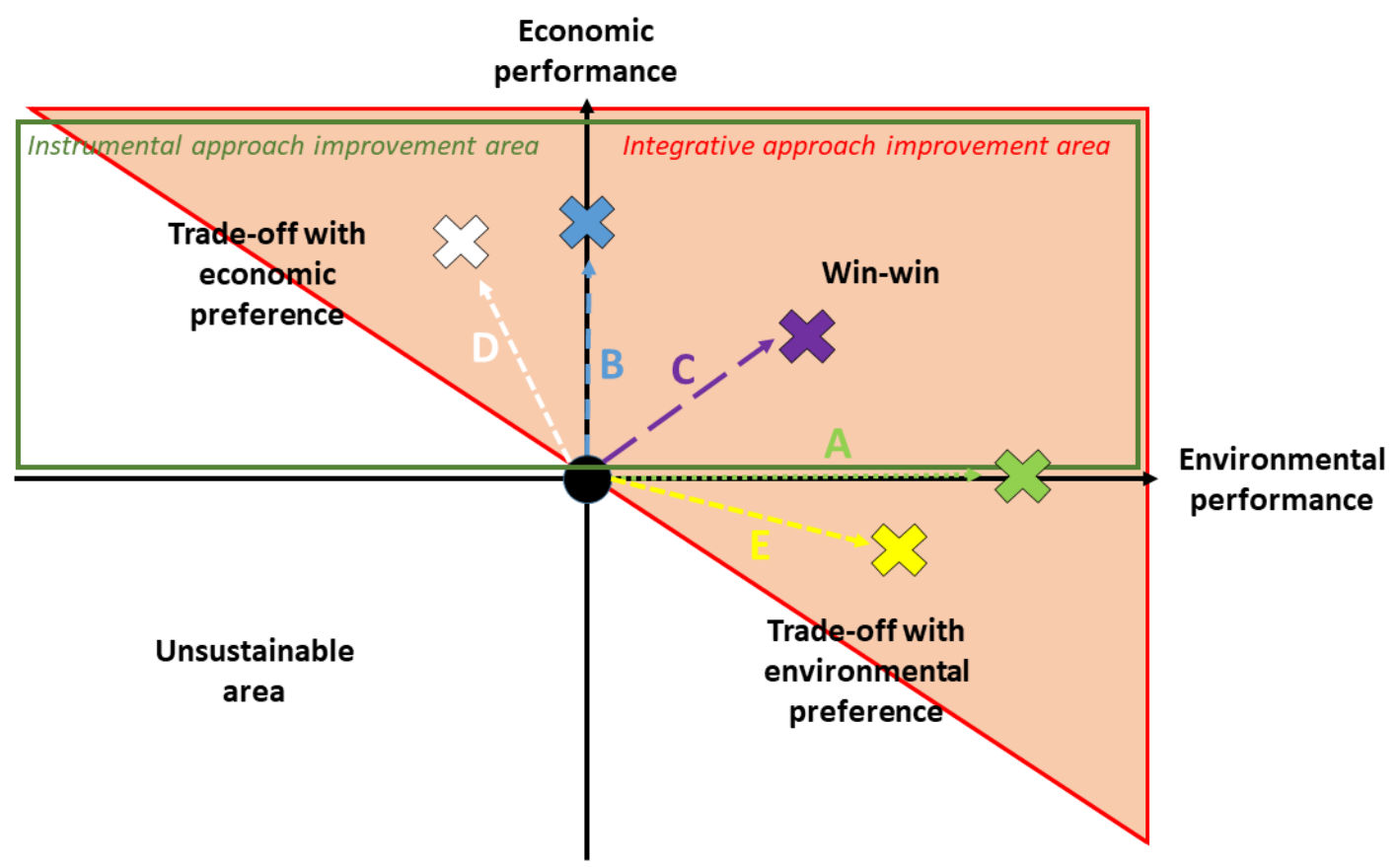

Figure 11. Eco-intensity improvement paths

The application of the method can lead to the development of interorganisational tensions within the supply chain (Brix-Asala et al. 2018), due to the modifications of existing supply chain practices (Van der Byl and Slawinski 2015). Structural, psychological and behavioural supply chain tensions can arise, which can affect the relational dynamics between supply chain members (Tura, Keränen, and Patala 2019). Although these types of tensions were not within the core aim of this work, they may affect the applicability of the method; hence, some initial findings from the case study application are discussed.

The structural tensions are related to the increased monitoring and controlling needs at the focal company and the potential reduced power positions of suppliers, either real or perceived, in each supplier-buyer dyad along the supply chain due to the lower bargaining power. This is usually linked to suppliers being smaller in size than buyers or substituted by buyers, a case that was valid in the majority of dyads within the 
case study, although some counterexamples, like dyads supplier 3.1-buyer 3 and supplier 1 -focal company, exist and were not affected by such structural tensions. While the indirect multi-tier approach facilitates the duties of the focal company in terms of data collection and control over its supply chain, a certain degree of monitoring is still required as a new additional task is required to the suppliers and the focal company is naturally responsible for the control activities as the environmental requirements stem from it.

On the other hand, psychological tensions refer to the potentially reduced motivation of suppliers to adhere to codes of conduct if they do not consider the environmental sustainability indicators critical to their business (Tura, Keränen, and Patala 2019).

Finally, behavioural tensions can arise due to the indirect multi-tier supply chain approach adopted by the method. As detailed in the case study overview, an additional $1^{\text {st }}$ tier supplier was initially involved in the study but decided to pull out to avoid sharing the data about its lower-tier suppliers. The willingness of $1^{\text {st }}$ tier suppliers to collect and share information about the lower-tier suppliers with the focal company has been identified as key enabler to achieve effective multi-tier SSCM (Dou, Zhu, and Sarkis 2017; Grimm, Hofstetter, and Sarkis 2014). However, it can determine interorganisational tensions due to additional pressure on suppliers to collect and share environmental data with their customers (Tura, Keränen, and Patala 2019). This pressure would especially target $1^{\text {st }}$ tier suppliers that would be asked not only to meet the sustainability requirements of the focal company but also to forward these requirements to $2^{\text {nd }}$ tier suppliers in order to engage them into the assessment according to the recursive mechanism logic (Tura, Keränen, and Patala 2019). In the absence of legislation requirements to force suppliers to assess the sustainability performance of 
their own suppliers, companies need to seek alternative options to overcome such tensions. While the power asymmetry in each buyer-supplier dyad has been identified as a key factor affecting the successful implementation of multi-tier SSCM (Grimm, Hofstetter, and Sarkis 2014; Dou, Zhu, and Sarkis 2017), this can also trigger additional structural tensions, potentially generating a poisonous escalation of tensions and needs to be carefully managed by powerful players in the supply chain.

\section{Implications for multi-tier SSCM performance assessment}

The case study presented in this work expands also the body of literature in the emerging field of multi-tier supply chain management for sustainability, focusing specifically in the area of multi-tier SSCM performance assessment. While the research on multi-tier supply chain management has stayed mostly at a conceptual level, the case study provided an empirical application of the multi-tier indirect approach theorised by Tachizawa and Wong (2014). The case study demonstrated a successful implementation of cross-tier collaboration in the area of SSCM performance assessment (Mueller, dos Santos, and Seuring 2009; Koh, Gunasekaran, and Tseng 2012; Tachizawa and Wong 2014), with the focal company able to assess the sustainability performance up to the $2^{\text {nd }}$ tier upstream despite not having visibility beyond its $1^{\text {st }}$ tier suppliers. The application of the method thus opens interesting opportunities to effectively achieve a supply chainwide sustainability assessment adopting a cascading assessment of suppliers' sustainability performance (Schöggl, Fritz, and Baumgartner 2016).

The multi-tier indirect approach was implemented in the case study through a bidirectional information-sharing mechanism. On one hand, the information-sharing mechanism moved upstream, as the focal company pressured its suppliers to adopt a simplified standardised data collection tool to gather sustainability-related information and to forward this tool to lower-tier suppliers in order to obtain information about their 
sustainability performance (Tachizawa and Wong 2014). The standardised data collection tool thus supported supply chain coordination as well (Tachizawa and Wong 2014; Ciliberti et al. 2009).

On the other hand, the downstream information-sharing mechanism involved the actual forwarding of the requested requirements downstream to the focal company. These information-sharing mechanisms require a certain degree of standardisation to allow direct suppliers to obtain sustainability information from the focal firm's indirect suppliers (Ciliberti et al. 2009). This was achieved in this research by simplifying the data collection process thanks to the black box approach, in order to "reduce the effort of both the information gatherer/assessor and that of the information provider in order to foster supply chain-wide sustainability assessment" (Schöggl, Fritz, and Baumgartner 2016). The data collection at the company level limits the burden of data collection for upstream suppliers and requires limited effort from the focal company thanks to the indirect approach. The data collection tool used in this case study could inform any potential future standard development to apply the specific method for sustainability assessment in supply chains.

Finally, the assessment features the adoption of primary data sourced from actual practice along the entire supply chain, managing to achieve a more detailed understanding of the supply chain sustainability performance. The level of granularity reached is much more detailed compared to methods adopting generic data, such as LCA, offering an increased support to decision makers to differentiate between alternative suppliers and supply chain branches with similar design, but potentially significantly different performance.

\section{Implications for practitioners}

The outputs obtained through the application of the method can directly support supply 
chain managers, both in the supplier selection and evaluation process and in the identification of hotspots to guide operational improvement, as highlighted in the 'Results' section. Moreover, the application of the method offered insights on how the method and its outputs could support practitioners in addressing SSCM tensions.

Such tensions are inherently resulting from the combination of multidimensional sustainability issue with the pressure originating from multiple stakeholders (Fayezi, Zomorrodi, and Bals 2018). These tensions primarily target procurement professionals within focal companies, as they are the main interface between the organisation and its supply chain, generating procurement sustainability tensions (Fayezi, Zomorrodi, and Bals 2018). From a focal company perspective, the indirect supply chain management approach can practically help to distribute tensions across organisations part of the supply chain by transferring part of sustainability responsibilities and associated risks to suppliers and sub-suppliers (Fayezi, Zomorrodi, and Bals 2018). This is achieved at a first stage by sharing the responsibilities of data collection with suppliers, maintaining focal company directly in charge of the data collection only within its organisational boundaries, as the case study demonstrated.

Furthermore, the identification of hotspots contributes towards the goal of tensions distribution by clearly identifying the impact pathway along the supply chain and having a data-driven support to implement operational changes within the supply chain to improve sustainability performance. The objective way of quantifying environmental impacts along the supply chain offered by the method applied using primary data sourced from actual practice, allows a better understanding of the sustainability issues within the supply chain, and facilitates discussions on improvements based on hard evidence, which could help alleviating tensions arising from different (or lack of) understanding or measuring methods adopted by different 
organisations along the supply chain. However, the implementation on a large scale of an indirect multi-tier approach needs to be supported by contractual agreements between organisations to achieve a mutual understanding of sustainability requirements, otherwise there is a risk to simply transfer pressure and associated tensions along the supply chain exploiting asymmetrical power distribution (Fayezi, Zomorrodi, and Bals 2018).

The integrative approach proposed and applied in this work can also support changing the dominant perspective in supply chain management practice moving away from an instrumental approach in managing tensions between sustainability dimensions. In a context where sustainability becomes increasingly important for customers and stakeholders, practitioners can benefit from understanding that they can adopt approaches, such as the one proposed in this work, where there is no direct priority on the economic dimension, but rather environmental impact reduction could be pursued even at the expense of economic performance, as in path E of Figure 11.

\section{Limitations of the research}

As every piece of research, this work is not immune from limitations. First, given the exploratory nature of the study, this was limited to a holistic single case study in an international machinery supply chain. As such, the case study presented in this work shares limitations of this case study design. Operational details within the supply chain were not examined (Yin 2003) and the results of the application of the method were affected by the data fed into the mathematical model as inputs. Since each organisation was responsible for its internal self-assessment, a reliable mechanism to verify the quality of environmental data provided by suppliers needs to be identified in the future. Moreover, the majority of organisations were quite structured with dedicated managers to cover sustainability issues because of their size. Future research is required to 
investigate the applicability of the method in supply chains dominated by small and medium enterprises or in different industries in order to generalise the findings and to strengthen the external validity of the case study through replication logic (Meredith et al. 1989; Yin 2003). Second, the case study was limited to a portion of the supply chain of the product under analysis, therefore an application of the method to the entire supply chain is still to be performed. This would allow verifying the applicability of the method on a larger scale and to understand the impact on sustainability associated to the plethora of small suppliers present in the majority of manufacturing supply chains. The extension of the research in this direction would also aim to explore the issue of inaccessibility of suppliers, whose participation to the assessment is currently voluntary, in order to investigate behavioural tensions arising in the supply chain. As the previous section detailed, in the absence of legislative requirements, focal companies need to find an effective way to make the recursive mechanism roll along the upstream supply chain. Finally, this study addressed the tensions between different dimensions of sustainability but did not fully explore other types of tensions potentially arising between different supply chain members as a result of the implementation of the proposed method, such as structural, psychological and behavioural supply chain tensions, which can affect the relational dynamics between supply chain members (Tura, Keränen, and Patala 2019). These tensions can arise due to the modifications of existing supply chain practices (Van der Byl and Slawinski 2015). A longitudinal study with additional qualitative data would serve this purpose in the future.

\section{Conclusions}

This work evaluated an indirect approach to assess the sustainability performance of a multi-tier supply chain through an eco-intensity method that features an integrative approach to address tensions between environmental and economic dimensions. The 
method was applied to an international machinery supply chain adopting single case study research. Six eco-intensity indicators were calculated for each organisation part of the supply chain, as well as for the supply chain under analysis. Moreover, the environmental backpack associated to the final product was calculated, which is the absolute environmental impact allocated to one unit of the final product.

The outputs of the method were functional to compare alternative parallel suppliers and to identify the eco-intensity hotspots along the supply chain in order to direct operational improvement, thus supporting decision making of supply chain managers to make the supply chain more sustainable. The selection of eco-intensity indicators to assess the sustainability performance of supply chains determines a shift from the traditional instrumental logic adopted in SSCM literature towards an integrative approach to address tensions between sustainability dimensions. Ecointensity performance improvements can be achieved even in the case of deterioration of the economic performance if this is accompanied by a disproportionally higher improvement in the environmental performance. Therefore, it offers a different lens on how tensions between the environmental and economic sustainability dimensions can be addressed compared to the instrumental logic.

As a result, this work contributes to the existing SSCM literature in two ways. First, it advances the SSCM performance assessment field. This is obtained by adding an exploratory application of a successful implementation of an indirect multi-tier supply chain approach for the assessment of the sustainability performance of the supply chain, demonstrating its suitability in achieving a decentralised assessment in a supply chain even without visibility of the entire network. Moreover, the assessment is performed adopting empirical quantitative environmental data and thus capturing the specificity of each supply chain member, which is not achievable adopting generic data 
from databases. The case study thus acts as a forerunner demonstrating the applicability of the method in an operative multi-tier supply chain and paving the way for the sustainability assessment of extended supply chains.

Second, it contributes to the SSCM tensions literature, by presenting a novel method that allows moving from the dominant instrumental logic to an integrative approach between the environmental and economic dimensions of sustainability in multi-tier supply chains, by assessing different dimensions simultaneously without an a priori predominance of any of them. The eco-intensity indicators adopted do not entail a profit-oriented priority between sustainability dimensions, but on the contrary manage to obtain a balanced evaluation of the environmental and economic dimensions of sustainability, coherently with the perfect substitutability of natural and economic capital theorised by weak sustainability. Therefore, this method could be used as a tool to support managing the tensions between the environmental and economic sustainability dimensions.

Finally, having implemented the method within an operative supply chain, the case study also serves as empirical evidence of how tensions can be addressed at the stage of sustainable strategy implementation, where the performance assessment method stands as the first step to guide operational improvements to enhance the sustainability of the supply chain.

\section{Acknowledgements}

This research was supported by a University of Strathclyde Research Studentship.

\section{References}

Acquaye, Adolf, Andrea Genovese, John Barrett, and S.C. Lenny Koh. 2014. 
2013-0419.

Ahi, Payman, and Cory Searcy. 2015. 'An Analysis of Metrics Used to Measure Performance in Green and Sustainable Supply Chains'. Journal of Cleaner Production 86 (August). Elsevier Ltd: 360-377. doi:10.1016/j.jclepro.2014.08.005. Azadi, Majid, Amir Shabani, Mohsen Khodakarami, and Reza Farzipoor Saen. 2015. 'Planning in Feasible Region by Two-Stage Target-Setting DEA Methods: An Application in Green Supply Chain Management of Public Transportation Service Providers'. Transportation Research Part E: Logistics and Transportation Review 70. Elsevier Ltd: 324-338. doi:10.1016/j.tre.2014.12.009.

Bask, Anu, Merja Halme, Markku Kallio, and Markku Kuula. 2013. 'Consumer Preferences for Sustainability and Their Impact on Supply Chain ManagementThe Case of Mobile Phones'. International Journal of Physical Distribution \& Logistics Management 43 (5/6): 380-406. doi:10.1108/S14793563(2012)000012B005.

Beavis, Lynn. 2015. 'M\&S Takes an Interest in Its Suppliers' Green Credentials'. The Guardian.

Björklund, Maria, Uni Martinsen, and Mats Abrahamsson. 2012. 'Performance Measurements in the Greening of Supply Chains'. Supply Chain Management: An International Journal 17 (1): 29-39. doi:10.1108/13598541211212186.

Bloemhof, Jacqueline, and Grit Walther. 2016. 'Life Cycle Sustainable Assessment'. Bouchery, Yann, Asma Ghaffari, Zied Jemai, and Yves Dallery. 2012. 'Including Sustainability Criteria into Inventory Models'. European Journal of Operational Research 222 (2). Elsevier B.V.: 229-240. doi:10.1016/j.ejor.2012.05.004. Brandenburg, Marcus. 2015. 'Low Carbon Supply Chain Configuration for a New Product - a Goal Programming Approach'. International Journal of Production 
Research 53 (21): 1-23. doi:10.1080/00207543.2015.1005761.

Brennan, Geraldine, and Mike Tennant. 2018. 'Sustainable Value and Trade-Offs:

Exploring Situational Logics and Power Relations in a UK Brewery's Malt Supply

Network Business Model'. Business Strategy and the Environment 27: 621-630.

doi:10.1002/bse.2067.

Brix-Asala, Carolin, Anne Kristin Geisbüsch, Philipp Christopher Sauer, Patrick

Schöpflin, and Axel Zehendner. 2018. 'Sustainability Tensions in Supply Chains:

A Case Study of Paradoxes and Their Management'. Sustainability 10 (2): 1-20. doi:10.3390/su10020424.

Charmondusit, K., S. Phatarachaisakul, and P. Prasertpong. 2014. 'The Quantitative

Eco-Efficiency Measurement for Small and Medium Enterprise: A Case Study of

Wooden Toy Industry'. Clean Technologies and Environmental Policy 16 (5):

935-945. doi:10.1007/s10098-013-0693-4.

Christopher, Martin. 2011. Logistics \& Supply Chain Management. Paerson Education. doi:10.1007/s12146-007-0019-8.

Ciliberti, Francesco, Gerard de Groot, Job de Haan, and Pierpaolo Pontrandolfo. 2009.

'Codes to Coordinate Supply Chains: SMEs' Experiences with SA8000'. Supply

Chain Management: An International Journal 14 (2): 117-127.

doi:10.1108/13598540910941984.

Colicchia, Claudia, Alessandro Creazza, Fabrizio Dallari, and Marco Melacini. 2015.

'Eco-Efficient Supply Chain Networks: Development of a Design Framework and Application to a Real Case Study'. Production Planning \& Control 7287

(November): 1-12. doi:10.1080/09537287.2015.1090030.

Costanza, Robert, and Herman E Daly. 1992. 'Natural Capital and Sustainable

Development'. Conservation Biology 6 (1): 37-46. 
Daddi, Tiberio, Domenico Ceglia, Guia Bianchi, and Marcia Dutra de Barcellos. 2019. 'Paradoxical Tensions and Corporate Sustainability: A Focus on Circular Economy Business Cases'. Corporate Social Responsibility and Environmental Management, 1-11. doi:10.1002/csr.1719.

Dey, Prasanta Kumar, and Walid Cheffi. 2013. 'Green Supply Chain Performance Measurement Using the Analytic Hierarchy Process: A Comparative Analysis of Manufacturing Organisations'. Production Planning \& Control 24 (8-9): 702-720. doi:10.1080/09537287.2012.666859.

Dou, Yijie, Qinghua Zhu, and Joseph Sarkis. 2017. 'Green Multi-Tier Supply Chain Management: An Enabler Investigation'. Journal of Purchasing and Supply Management. Elsevier Ltd, 1-13. doi:10.1016/j.pursup.2017.07.001.

EcoTransIT World Initiative. 2016. 'Ecological Transport Information Tool for Worldwide Transports: Methodology and Data Update'. EcoTransIT World Initiaitive (EWI).

Egilmez, Gokhan, Murat Kucukvar, Omer Tatari, and M. Khurrum S. Bhutta. 2014. 'Supply Chain Sustainability Assessment of the U.S. Food Manufacturing Sectors: A Life Cycle-Based Frontier Approach'. Resources, Conservation and Recycling 82 (January). Elsevier B.V.: 8-20. doi:10.1016/j.resconrec.2013.10.008. European Environment Agency. 1999. Making Sustainability Accountable: EcoEfficiency, Resource Productivity and Innovation. Proceedings of a Workshop on the Occasion of the Fifth Anniversary of the European Environment Agency (EEA). European Union. 2003. 'Commission Recommendation of 6 May 2003 Concerning the Definition of Micro, Small and Medium-Sized Enterprises'. Official Journal of the European Union. doi:10.1017/CBO9781107415324.004.

Fabbe-Costes, Nathalie, Christine Roussat, and Jacques Colin. 2011. 'Future 
Sustainable Supply Chains: What Should Companies Scan?' International Journal of Physical Distribution \& Logistics Management 41 (3): 228-252. doi:10.1108/S1479-3563(2012)000012B007.

Fayezi, Sajad, Maryam Zomorrodi, and Lydia Bals. 2018. 'Procurement Sustainability Tensions: An Integrative Perspective'. International Journal of Physical Distribution \& Logistics Management 48 (6): 586-609. doi:10.1108/IJPDLM-052013-0155.

Frota Neto, J. Quariguasi, J.M. Bloemhof-Ruwaard, J.a.E.E. van Nunen, and E. van Heck. 2008. 'Designing and Evaluating Sustainable Logistics Networks'. International Journal of Production Economics 111 (2): 195-208. doi:10.1016/j.ijpe.2006.10.014.

Genovese, Andrea, S.C. Lenny Koh, Niraj Kumar, and Pradhumn Kumar Tripathi. 2013. 'Exploring the Challenges in Implementing Supplier Environmental Performance Measurement Models: A Case Study’. Production Planning \& Control 25 (13-14): 1198-1211. doi:10.1080/09537287.2013.808839.

Gimenez, Cristina, and Elcio M. Tachizawa. 2012. 'Extending Sustainability to Suppliers: A Systematic Literature Review'. Supply Chain Management: An International Journal 17 (5): 531-543. doi:10.1108/13598541211258591.

Grimm, Jörg H., Joerg S. Hofstetter, and Joseph Sarkis. 2014. 'Critical Factors for SubSupplier Management: A Sustainable Food Supply Chains Perspective'. International Journal of Production Economics 152. Elsevier: 159-173. doi:10.1016/j.ijpe.2013.12.011.

Hahn, Tobias, Jonatan Pinkse, Lutz Preuss, and Frank Figge. 2015. 'Tensions in Corporate Sustainability: Towards an Integrative Framework'. Journal of Business Ethics 127: 297-316. doi:10.1007/s10551-014-2047-5. 
Harris, Irina, Mohamed Naim, Andrew Palmer, Andrew Potter, and Christine Mumford. 2011. 'Assessing the Impact of Cost Optimization Based on Infrastructure Modelling on CO2 Emissions'. International Journal of Production Economics 131 (1). Elsevier: 313-321. doi:10.1016/j.ijpe.2010.03.005.

Hartmann, Julia, and Sabine Moeller. 2014. 'Chain Liability in Multitier Supply Chains? Responsibility Attributions for Unsustainable Supplier Behavior'. Journal of Operations Management 32 (5). Elsevier B.V.: 281-294. doi:10.1016/j.jom.2014.01.005.

Hassini, Elkafi, Chirag Surti, and Cory Searcy. 2012. 'A Literature Review and a Case Study of Sustainable Supply Chains with a Focus on Metrics'. International Journal of Production Economics 140 (1). Elsevier: 69-82. doi:10.1016/j.ijpe.2012.01.042.

Hervani, Aref A., Marilyn M. Helms, and Joseph Sarkis. 2005. 'Performance Measurement for Green Supply Chain Management'. Benchmarking: An International Journal 12 (4): 330-353.

Hopwood, Bill, Mary Mellor, and Geoff O’Brien. 2005. 'Sustainable Development: Mapping Different Approaches'. Sustainable Development 13: 38-52. Huppes, Gjalt, and Masanobu Ishikawa. 2005. 'Eco-Efficiency and Its Terminology'. Journal of Industrial Ecology 9 (4): 43-46. doi:10.1162/108819805775247891. Jabbour, Charbel Jose Chiappetta, Ana Beatriz Lopes de Sousa Jabbour, and Joseph Sarkis. 2018. 'Unlocking Effective Multi-Tier Supply Chain Management for Sustainability through Quantitative Modelling: Lessons Learned and Discoveries to Be Made'. International Journal of Production Economics. Elsevier B.V. doi:https://doi.org/10.1016/j.ijpe.2018.08.029.

Joa, Bettina, Heidi Hottenroth, Norbert Jungmichel, and Mario Schmidt. 2014. 
'Introduction of a Feasible Performance Indicator for Corporate Water Accounting - a Case Study on the Cotton Textile Chain'. Journal of Cleaner Production 82 (November). Elsevier Ltd: 143-153. doi:10.1016/j.jclepro.2014.06.075.

Kannegiesser, M., and H.-O. Günther. 2013. ‘Sustainable Development of Global Supply Chains_-Part 1: Sustainability Optimization Framework'. Flexible Services and Manufacturing Journal 26 (1-2): 24-47. doi:10.1007/s10696-013-9176-5.

Koh, Lenny S. C., A. Gunasekaran, and C. S. Tseng. 2012. 'Cross-Tier Ripple and Indirect Effects of Directives WEEE and RoHS on Greening a Supply Chain'. International Journal of Production Economics 140 (1). Elsevier: 305-317. doi:10.1016/j.ijpe.2011.05.008.

Koh, Lenny S.C., Andrea Genovese, Adolf A. Acquaye, Paul Barratt, Nasir Rana, Johan Kuylenstierna, and David Gibbs. 2012. 'Decarbonising Product Supply Chains: Design and Development of an Integrated Evidence-Based Decision Support System - the Supply Chain Environmental Analysis Tool (SCEnAT)'. International Journal of Production Research 51 (7): 2092-2109. doi:10.1080/00207543.2012.705042.

Kovács, Gyöngyi. 2008. 'Corporate Environmental Responsibility in the Supply Chain'. Journal of Cleaner Production 16 (15): 1571-1578. doi:10.1016/j.jclepro.2008.04.013.

Krikke, Harold. 2011. 'Impact of Closed-Loop Network Configurations on Carbon Footprints: A Case Study in Copiers'. Resources, Conservation and Recycling 55 (12). Elsevier B.V.: 1196-1205. doi:10.1016/j.resconrec.2011.07.001. Low, Jonathan Sze Choong, Tobias Bestari Tjandra, Wen Feng Lu, and Hui Mien Lee. 2015. 'Adaptation of the Product Structure-Based Integrated Life Cycle Analysis (PSILA) Technique for Carbon Footprint Modelling and Analysis of Closed-Loop 
Production Systems'. Journal of Cleaner Production. Elsevier Ltd. doi:10.1016/j.jclepro.2015.09.095.

Mahdiloo, Mahdi, Reza Farzipoor Saen, and Ki Hoon Lee. 2015. 'Technical, Environmental and Eco-Efficiency Measurement for Supplier Selection: An Extension and Application of Data Envelopment Analysis'. International Journal of Production Economics 168. Elsevier: 279-289. doi:10.1016/j.ijpe.2015.07.010. Marshall, Donna, Lucy McCarthy, Ciarán Heavey, and Paul McGrath. 2014. 'Environmental and Social Supply Chain Management Sustainability Practices: Construct Development and Measurement'. Production Planning \& Control, no. August 2015: 1-18. doi:10.1080/09537287.2014.963726.

Matthews, Lee, Damien Power, Anne Touboulic, and Leonardo Marques. 2016. 'Building Bridges: Toward Alternative Theory of Sustainable Supply Chain Management'. Journal of Supply Chain Management 52 (1): 82-94. doi:10.1111/jscm.12097.

Mebratu, Desta. 1998. 'Sustainability and Sustainable Development'. Environmental Impact Assessment Review 18 (6): 493-520. doi:10.1016/S0195-9255(98)00019-5. Meinlschmidt, Jan, Martin C Schleper, and Kai Foerstl. 2018. 'Tackling the Sustainability Iceberg: A Transaction Cost Economics Approach to Lower Tier Sustainability Management'. International Journal of Operations \& Production Management 38 (10): 1888-1914.

Mele, F D, a M Kostin, G Guillen-Gosalbez, and L Jimenez. 2011. 'Multiobjective Model for More Sustainable Fuel Supply Chains. A Case Study of the Sugar Cane Industry in Argentina'. Industrial \& Engineering Chemistry Research 50 (9): 4939-4958. doi:10.1021/ie101400g.

Mena, Carlos, Andrew Humphries, and Thomas Y. Choi. 2013. 'Toward a Theory of 
Multi-Tier Supply Chain Management'. Journal of Supply Chain Management 49

(2): 58-77. doi:10.1111/jscm.12003.

Meredith, Jack R., Amitabh Raturi, Kwasi Amoako-Gyampah, and Bonnie Kaplane.

1989. 'Alternative Research Paradigms in Operations'. Journal of Operations

Management 8 (4): 297-326.

Michelsen, Ottar, and Annik Magerholm Fet. 2010. 'Using Eco-Efficiency in Sustainable Supply Chain Management; A Case Study of Furniture Production'. Clean Technologies and Environmental Policy 12 (5): 561-570. doi:10.1007/s10098-009-0266-8.

Michelsen, Ottar, Annik Magerholm Fet, and Alexander Dahlsrud. 2006. 'EcoEfficiency in Extended Supply Chains: A Case Study of Furniture Production'. Journal of Environmental Management 79 (3): 290-297. doi:10.1016/j.jenvman.2005.07.007.

Miemczyk, Joe, Thomas E. Johnsen, and Monica Macquet. 2012. 'Sustainable Purchasing and Supply Management: A Structured Literature Review of Definitions and Measures at the Dyad, Chain and Network Levels'. Supply Chain Management: An International Journal 17 (5): 478-496. doi:10.1108/13598541211258564.

Mintcheva, Verginia. 2005. 'Indicators for Environmental Policy Integration in the Food Supply Chain (the Case of the Tomato Ketchup Supply Chain and the Integrated Product Policy)'. Journal of Cleaner Production 13 (7): 717-731. doi:10.1016/j.jclepro.2004.01.008.

Montabon, Frank, Mark Pagell, and Zhaohui Wu. 2016. 'Making Sustainability Sustainable'. Journal of Supply Chain Management 52 (2): 11-27. Montoya-Torres, Jairo R, Edgar Gutierrez-Franco, and Edgar E Blanco. 2015. 
'Conceptual Framework for Measuring Carbon Footprint in Supply Chains'.

Production Planning \& Control 26 (4): 265-279.

doi:10.1080/09537287.2014.894215.

MSCI. 2015. Global Industry Classification Standard.

Mueller, Martin, Virginia Gomes dos Santos, and Stefan Seuring. 2009. 'The

Contribution of Environmental and Social Standards towards Ensuring Legitimacy in Supply Chain Governance'. Journal of Business Ethics 89 (4): 509-523. doi:10.1007/s10551-008-0013-9.

Nasir, Mohammed Haneef Abdul, Andrea Genovese, Adolf A. Acquaye, S. C.L. Koh, and Fred Yamoah. 2017. 'Comparing Linear and Circular Supply Chains: A Case Study from the Construction Industry'. International Journal of Production Economics 183. Elsevier: 443-457. doi:10.1016/j.ijpe.2016.06.008.

Ness, Barry, Evelin Urbel-Piirsalu, Stefan Anderberg, and Lennart Olsson. 2007. 'Categorising Tools for Sustainability Assessment'. Ecological Economics 60 (3): 498-508. doi:10.1016/j.ecolecon.2006.07.023.

O’Rourke, Dara. 2014. 'The Science of Sustainable Supply Chains'. Science 344 (6188): 1124-1128.

Oberkampf, William L., and Christopher J. Roy. 2010. 'Modeling and Computational Simulation'. In Verification and Validation in Scientific Computing, 83-144.

Quariguasi Frota Neto, J., G. Walther, J. Bloemhof, J. A E E van Nunen, and T. Spengler. 2009. 'A Methodology for Assessing Eco-Efficiency in Logistics Networks'. European Journal of Operational Research 193 (3). Elsevier B.V.: 670-682. doi:10.1016/j.ejor.2007.06.056.

Salvado, Miguel, Susana Azevedo, João Matias, and Luís Ferreira. 2015. 'Proposal of a Sustainability Index for the Automotive Industry'. Sustainability 7 (2): 2113-2144. 
doi:10.3390/su7022113.

Sauer, Philipp C., and Stefan Seuring. 2018. 'Extending the Reach of Multi-Tier Sustainable Supply Chain Management - Insights from Mineral Supply Chains'. International Journal of Production Economics. Elsevier B.V. doi:10.1016/j.ijpe.2018.05.030.

Savino, M M, R Manzini, and a Mazza. 2015. 'Environmental and Economic Assessment of Fresh Fruit Supply Chain through Value Chain Analysis. A Case Study in Chestnuts Industry’. Production Planning \& Control 26 (1): 1-18. doi:10.1080/09537287.2013.839066.

Schmidt, Mario, and Regina Schwegler. 2008. 'A Recursive Ecological Indicator System for the Supply Chain of a Company'. Journal of Cleaner Production 16 (15): 1658-1664. doi:10.1016/j.jclepro.2008.04.006.

Schöggl, Josef P., Morgane M. C. Fritz, and Rupert J. Baumgartner. 2016. 'Toward Supply Chain-Wide Sustainability Assessment: A Conceptual Framework and an Aggregation Method to Assess Supply Chain Performance'. Journal of Cleaner Production 131: 822-835. doi:10.1016/j.jclepro.2016.04.035.

Seuring, Stefan, and Martin Müller. 2008. 'From a Literature Review to a Conceptual Framework for Sustainable Supply Chain Management'. Journal of Cleaner Production 16 (15): 1699-1710. doi:10.1016/j.jclepro.2008.04.020.

Sigala, Marianna. 2008. 'A Supply Chain Management Approach for Investigating the Role of Tour Operators on Sustainable Tourism: The Case of TUI'. Journal of Cleaner Production 16 (15): 1589-1599. doi:10.1016/j.jclepro.2008.04.021.

Slack, Nigel, Alistair Brandon-Jones, and Robert Johnston. 2013. Operations Management. Harlow: Paerson Education.

Soysal, M., J. M. Bloemhof-Ruwaard, and J. G. A. J. Van Der Vorst. 2014. 'Modelling 
Food Logistics Networks with Emission Considerations: The Case of an

International Beef Supply Chain'. International Journal of Production Economics

152. Elsevier: 57-70. doi:10.1016/j.ijpe.2013.12.012.

Sundarakani, Balan, Robert De Souza, Mark Goh, Stephan M. Wagner, and Sushmera Manikandan. 2010. 'Modeling Carbon Footprints across the Supply Chain'. International Journal of Production Economics 128. Elsevier: 43-50. doi:10.1016/j.ijpe.2010.01.018.

Tachizawa, Elcio M., and Chee Yew Wong. 2014. 'Towards a Theory of Multi-Tier Sustainable Supply Chains: A Systematic Literature Review'. Supply Chain Management: An International Journal 19 (5/6): 643-663. doi:10.1108/SCM-022014-0070.

Taticchi, Paolo, Flavio Tonelli, and Roberto Pasqualino. 2013. 'Performance Measurement of Sustainable Supply Chains: A Literature Review and a Research Agenda'. International Journal of Productivity and Performance Management 62 (8): 782-804.

Tseng, Ming-Lang, Kim-Hua Tan, Ming Lim, Ru-Jen Lin, and Yong Geng. 2013. 'Benchmarking Eco-Efficiency in Green Supply Chain Practices in Uncertainty'. Production Planning \& Control 7287 (July 2014): 1-12. doi:10.1080/09537287.2013.808837.

Tsoulfas, Giannis T., and Costas P. Pappis. 2008. 'A Model for Supply Chains Environmental Performance Analysis and Decision Making'. Journal of Cleaner Production 16 (15): 1647-1657. doi:10.1016/j.jclepro.2008.04.018.

Tugnoli, A., F. Santarelli, and V. Cozzani. 2008. 'An Approach to Quantitative Sustainability Assessment in the Early Stages of Process Design'. Environmental Science \& Technology 42 (12): 4555-4562. doi:10.1021/es702441r. 
Tuni, Andrea, and Athanasios Rentizelas. 2018. 'An Innovative Eco-Intensity Based Method for Assessing Extended Supply Chain Environmental Sustainability'. International Journal of Production Economics. Elsevier B.V. doi:10.1016/j.ijpe.2018.08.028.

Tuni, Andrea, Athanasios Rentizelas, and Alex Duffy. 2018. 'Environmental Performance Measurement for Green Supply Chains'. International Journal of Physical Distribution \& Logistics Management 48 (8): 765-793. doi:10.1108/IJPDLM-02-2017-0062.

Tura, Nina, Joona Keränen, and Samuli Patala. 2019. 'The Darker Side of Sustainability: Tensions from Sustainable Business Practices in Business Networks'. Industrial Marketing Management. Elsevier. doi:10.1016/j.indmarman.2018.09.002.

Ukidwe, Nandan U, and Bhavik R Bakshi. 2005. 'Natural versus Economic Capital in Industrial Supply Networks - Implications for Outsourcing and Sustainability'. Environmental Science \& Technology Technology 39 (24): 9759-9769. Vachon, Stephan, and Zhimin Mao. 2008. 'Linking Supply Chain Strength to Sustainable Development: A Country-Level Analysis'. Journal of Cleaner Production 16 (15): 1552-1560. doi:10.1016/j.jclepro.2008.04.012.

Van Caneghem, J., C. Block, P. Cramm, R. Mortier, and C. Vandecasteele. 2010. 'Improving Eco-Efficiency in the Steel Industry: The ArcelorMittal Gent Case'. Journal of Cleaner Production 18 (8). Elsevier Ltd: 807-814. doi:10.1016/j.jclepro.2009.12.016.

Van der Byl, Connie A., and Natalie Slawinski. 2015. 'Embracing Tensions in Corporate Sustainability: A Review of Research From Win-Wins and Trade-Offs to Paradoxes and Beyond'. Organization \& Environment 28 (1): 54-79. 
doi:10.1177/1086026615575047.

Varsei, Mohsen, Claudine Soosay, Behnam Fahimnia, and Joseph Sarkis. 2014. 'Framing Sustainability Performance of Supply Chains with Multidimensional Indicators'. Supply Chain Management: An International Journal 19 (3): 242-257. doi:10.1108/SCM-12-2013-0436.

Vasan, Arvind, Bhanu Sood, and Michael Pecht. 2014. 'Carbon Footprinting of Electronic Products'. Applied Energy 136. Elsevier Ltd: 636-648. doi:10.1016/j.apenergy.2014.09.074.

Veleva, Vesela, Maureen Hart, Tim Greiner, and Cathy Crumbley. 2003. 'Indicators for Measuring Environmental Sustainability: A Case Study of the Pharmaceutical Industry'. Benchmarking: An International Journal 10 (2): 107-119.

Wang, Jiang Jiang, You Yin Jing, Chun Fa Zhang, and Jun Hong Zhao. 2009. 'Review on Multi-Criteria Decision Analysis Aid in Sustainable Energy Decision-Making'. Renewable and Sustainable Energy Reviews 13 (9): 2263-2278. doi:10.1016/j.rser.2009.06.021.

WBCSD. 2000. Eco-Efficiency. Creating More Value with Less Impact. World Business Council for Sustainable Development.

Wiedmann, Thomas O., Manfred Lenzen, and John R. Barrett. 2009. 'Companies on the Scale Comparing and Benchmarking the Sustainability Performance of Businesses'. Journal of Industrial Ecology 13 (3): 361-383. doi:10.1111/j.15309290.2009.00125.x.

Wilhelm, Miriam, Constantin Blome, Vikram Bhakoo, and Antony Paulraj. 2016. 'Sustainability in Multi-Tier Supply Chains: Understanding the Double Agency Role of the First-Tier Supplier'. Journal of Operations Management 41. Elsevier Ltd: 42-60. doi:10.1016/j.jom.2015.11.001. 
Wu, Chong, and David Barnes. 2016. ‘An Integrated Model for Green Partner Selection and Supply Chain Construction'. Journal of Cleaner Production 112. Elsevier Ltd: 2114-2132. doi:10.1016/j.jclepro.2015.02.023.

Xiao, Chengyong, Miriam Wilhelm, Taco van der Vaart, and Dirk Pieter van Donk. 2019. 'Inside the Buying Firm: Exploring Responses to Paradoxical Tensions in Sustainable Supply Chain Management'. Journal of Supply Chain Management 55 (1): 3-20. doi:10.1111/jscm.12170.

Yin, Robert K. 2003. Case Study Research: Design and Methods. Sage Publications. Thousand Oaks: Sage Publications. doi:10.1097/FCH.0b013e31822dda9e.

Zhou, Li, Hella Tokos, Damjan Krajnc, and Yongrong Yang. 2012. 'Sustainability Performance Evaluation in Industry by Composite Sustainability Index'. Clean Technologies and Environmental Policy 14 (5): 789-803. doi:10.1007/s10098012-0454-9.

\section{Appendixes}

\section{Appendix 1: Nomenclature}

\begin{tabular}{cl} 
Abbreviation & Meaning \\
\hline$e$ & Environmental indicator \\
$E B P$ & Environmental backpack \\
$E B P_{e i k}$ & Environmental backpack with respect to environmental indicator $e$ of \\
& organisation $i$ associated to its output product $k$ \\
$E I$ & Eco-intensity \\
$E I_{e i k}$ & Eco-intensity with respect to environmental indicator $e$ of organisation $i$ \\
$E I_{e j k}$ & associated to its output product $k$ \\
& Eco-intensity with respect to environmental indicator $e$ of supplier $j$ \\
$E P$ & associated to its output product $k$ \\
& Environmental performance
\end{tabular}


$E P_{e i} \quad$ Environmental performance with respect to environmental indicator $e$ of organisation $i$

$E P_{e j i}^{t r} \quad$ Environmental performance of transport from supplier $j$ to customer $i$ with respect to the environmental indicator $e$

$i \quad$ Customer of each dyad for each iteration of the recursive mechanism

$j \quad$ Supplier of each dyad for each iteration of the recursive mechanism

$k \quad$ Products offered from an organisation $i$ to its customer for each iteration of the recursive mechanism

$n \quad$ Intermediate products purchased by organisation $i$ from supplier $j$ for its output product $k$ for each iteration of the recursive mechanism

Q Quantity

$Q_{i j k n} \quad$ Quantity of product $n$ purchased by organisation $i$ from supplier $j$ for its output product $k$

$P \quad$ Price

$P_{i j k n} \quad$ Price of product $n$ purchased by organisation $i$ from supplier $j$ for its output product $k$

T Turnover

$T_{i} \quad$ Turnover of organisation $i$

$T_{i k} \quad$ Turnover of organisation $i$ generated by product $k$

$T_{i j k} \quad$ Turnover of supplier $j$ generated by organisation $i$ through the purchase of product $k$

$T_{j} \quad$ Turnover of supplier $j$

tr Transport

\section{Appendix 2: Equations to integrate the environmental impact of transport}

Equations A1.1, A1.2 and A1.3 introduce three alternative formulations to calculate the supply chain eco-intensity for the 'energy consumption' and 'emissions to air' environmental category, including transport activities, whereas Equations A2.1, A2.2 and A2.3 introduce three alternative formulations to calculate the environmental backpack for the 'energy consumption' and 'emissions to air' environmental category, including transport activities. The following equations add the $\sum_{\boldsymbol{j}} \boldsymbol{E} \boldsymbol{P}_{\boldsymbol{e} \boldsymbol{j} \boldsymbol{i}}^{\boldsymbol{t r}}$ term to the equations introduced in Tuni and Rentizelas (2018), which is the environmental performance of transport from supplier $j$ to customer $i$ with respect to the environmental indicator $e$ and is derived from the EcoTransIT tool for each dyadic transport link. 


$$
\begin{gathered}
E I_{e i k}=\frac{1}{T_{i k}}\left[\frac{T_{i k}}{T_{i}} E P_{e i}+\sum_{j} \boldsymbol{E} \boldsymbol{P}_{e j i}^{t r}+\sum_{j}\left(E I_{e j k} \sum_{n} Q_{i j k n} P_{i j k n}\right)\right] \\
E I_{e i k}=\frac{1}{T_{i k}}\left(\frac{T_{i k}}{T_{i}} E P_{e i}+\sum_{j} \boldsymbol{E} \boldsymbol{P}_{e j i}^{t r}+\sum_{j} E I_{e j k} T_{i j k}\right) \\
E I_{e i k}=\frac{1}{T_{i k}}\left(\frac{T_{i k}}{T_{i}} E P_{e i}+\sum_{j} \boldsymbol{E} \boldsymbol{P}_{e j i}^{t r}+\sum_{j} E I_{e j k} \frac{T_{i j k}}{T_{j}} T_{j}\right) \\
E B P_{e i k}=\frac{T_{i k}}{T_{i}} E P_{e i}+\sum_{j} \boldsymbol{E} \boldsymbol{P}_{e j i}^{t r}+\sum_{j}\left(E I_{e j k} \sum_{n} Q_{i j k n} P_{i j k n}\right) \\
E B P_{e i k}=\frac{T_{i k}}{T_{i}} E P_{e i}+\sum_{j} \boldsymbol{E} \boldsymbol{P}_{e j i}^{t r}+\sum_{j} E I_{e j k} T_{i j k} \\
E B P_{e i k}=\frac{T_{i k}}{T_{i}} E P_{e i}+\sum_{j} \boldsymbol{E} \boldsymbol{P}_{e j i}^{t r}+\sum_{j} E I_{e j k} \frac{T_{i j k}}{T_{j}} T_{j}
\end{gathered}
$$


Appendix 3: Data collection standardised spreadsheet

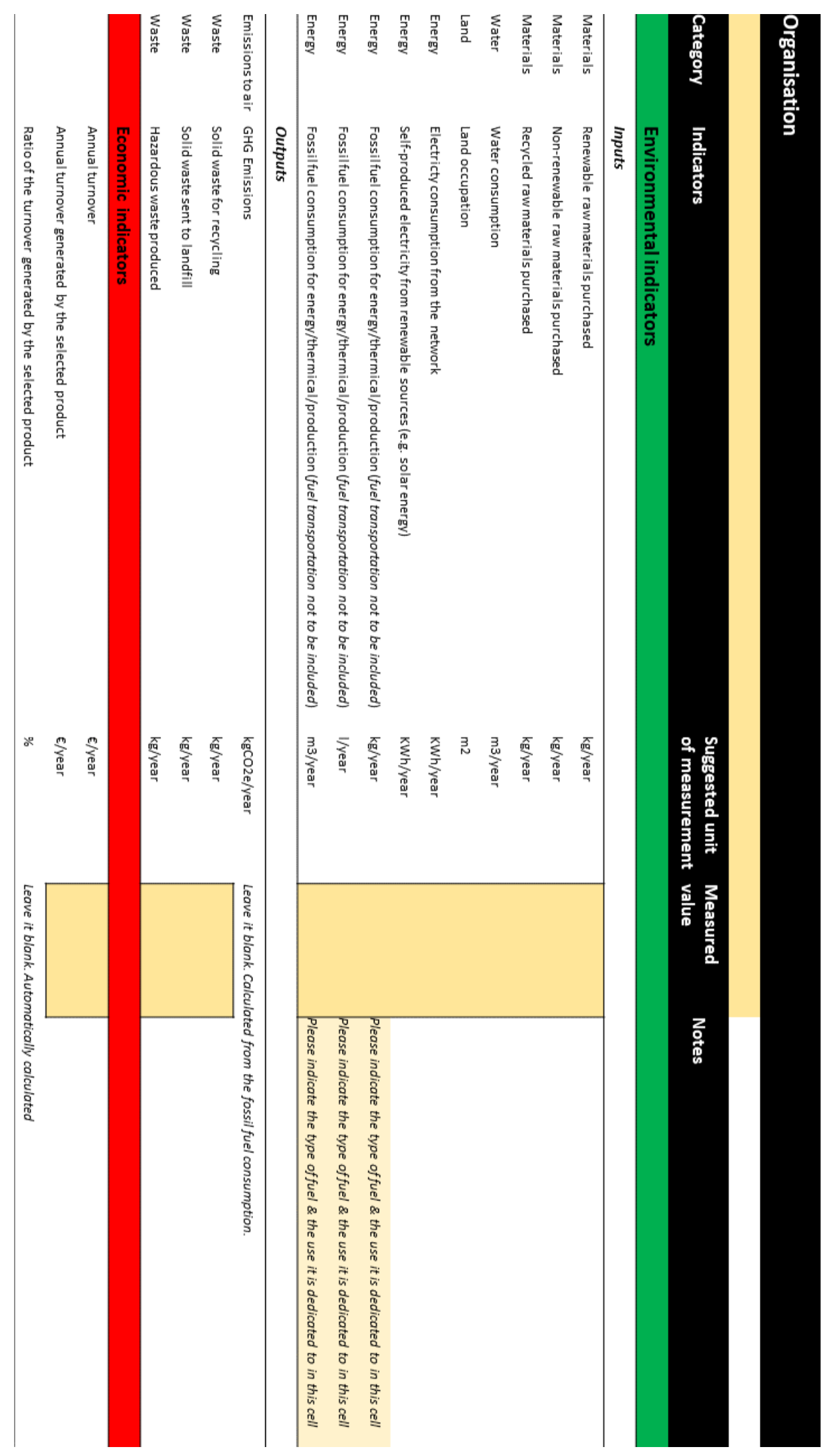

